\title{
El FACTOR LÍMITE EN LA FORMULACIÓN DEL DISCURSO DEL BRONCE DE LA Mancha: los Montes de TOledo COMO MOdelo
}

The limiting factor in La Mancha's Bronze Age formulation debate: the Montes de Toledo as a model

\section{ARTURO RUIZ TABOADA}

Dpto. de Prehistoria, $\mathrm{H}^{\mathrm{a}}$ Antigua y Arqueología. Universidad Complutense de Madrid. arruiz01@ucm.es (https://orcid.org/0000-0002-7957-2954)

\section{ReSumen:}

Cuarenta años de investigación en La Mancha han generado multitud de datos y teorías que tratan de explicar el desarrollo de la Edad del Bronce. Este artículo hace hincapié en los problemas derivados de una excesiva zonificación de la investigación y apuesta por la periferia como una de las claves para entender las diferentes dinámicas de ocupación del territorio. Determinar el papel del límite en relación con un centro cultural en las sociedades prehistóricas siempre ha sido objeto de debate. Dicho debate se incrementa al hablar de la Edad del Bronce peninsular, debido a su enorme atomización regional, sin que exista un consenso sobre sus límites e influencias. Esta atomización también se encuentra presente en el Bronce de La Mancha, cuya identidad viene dada por las múltiples comarcas limítrofes que lo integran. Se analiza la incidencia de este factor límite en la formulación del discurso tomando como modelo los Montes de Toledo, entidad geográfica independiente sin solución de continuidad con la penillanura.

Palabras clave: asentamiento, desplazamiento, Edad del Bronce, La Mancha, límite, Montes de Toledo.

\section{Abstract.}

This work focuses on the periphery as one of the keys to understand the Bronze Age after forty years of research in La Mancha region. It has always been a matter of debate the role of neighbouring lands in relation to a cultural centre in prehistoric societies. This debate increases when discussing the peninsular Bronze Age, due to its enormous regional atomization. The lack of consensus on its limits or the degree of relationship with the rest of the peninsular lands is still an issue. In the case of the Bronze Age in La Mancha, the Toledo Mountains can be used as a model to understand this limiting factor. The role of these surrounding areas in the formulation of the Bronze Age might help to understand different cultural and chronological developments within La Mancha and its surrounding areas.

Key words: settlement, mobility, Bronze Age, La Mancha, limit, Toledo Mountains. 
Cuatro décadas de intensa investigación en La Mancha no impiden tener la sensación de que sólo conocemos una mínima parte de los procesos de formación y desarrollo de la Edad del Bronce. Definida acertadamente como una arqueología de asentamientos (Fernández Posse et al. 2008: 14), la falta de datos ha sido el común denominador en todos los planteamientos teóricos propuestos hasta la fecha, ya sea desde el difusionismo (Nájera y Molina 1977; Nieto Gallo y Sánchez Meseguer 1980), funcionalismo (Chapman 1990) o el materialismo histórico (Gilman 1995). Hoy en día se tiende a invocar esta falta de datos como la principal causa de estancamiento, si bien es cierto que también asistimos a nuevos planteamientos centrados en aspectos tan dispares como el cambio climático o el mundo funerario (Nájera et al. 2010; Benítez de Lugo Enrich et al. 2014; Mejías Moreno et al. 2015; Santisteban et al. 2016; Blanco González et al. 2018; Benítez de Lugo Enrich 2018). Quizá el punto intermedio sea el equilibrio entre las diferentes posturas, asumiendo de forma crítica lo limitado de la muestra (Hodder y Hutson 2003). El Bronce de La Mancha desde luego cumple con la base de este último planteamiento: la percepción histórica está distorsionada, no existe el conocimiento objetivo y cualquier método parece admisible para comprender el pasado.

El gran número de intervenciones de los últimos años motivado por la denominada arqueología de gestión tampoco parece haber ayudado a desbloquear esta tendencia (Martínez Moratalla et al. 2002; García Huerta y Morales 2004; Benítez de Lugo et al. 2007; Morín de Pablos et al. 2007; Rojas Rodríguez Malo et al. 2010; Hernández Pérez 2016). Por otra parte, la sectorización de la investigación en La Mancha ha derivado en un excesivo localismo a la hora de analizar el registro arqueológico, en detrimento de un enfoque más global. Esta sectorización además ha visibilizado zonas en las que nunca se ha investigado, como el $\mathrm{S}$ de las provincias de Toledo y Cuenca, en plena Mancha, que ponen en evidencia la debilidad del método empleado (fig. 1). Así, la enorme producción escrita generada por los diferentes proyectos de investigación, entre ellos mi propia tesis doctoral (Ruiz Taboada 1998), contrasta con la escasa novedad de los temas tratados. Con el fin de evitar reiteraciones, este trabajo sólo menciona la bibliografía que inicia cada debate correspondiente y reconoce la falta de nuevos datos como principal problema para avanzar en el conocimiento del Bronce de La Mancha.
El objetivo es reflexionar sobre un tema relegado a un segundo plano como es el papel de los territorios limítrofes en la configuración del denominado Bronce de La Mancha. Para ello, vamos a tomar como ejemplo los Montes de Toledo. El punto de partida es la información publicada sobre la naturaleza y dispersión del asentamiento en La Mancha, revisando aquellos aspectos que tienen que ver con los modelos de ocupación propuestos y la documentación derivada de excavaciones arqueológicas. La intención es devolver el protagonismo perdido a las regiones periféricas que configuran La Mancha, erróneamente entendida como una única entidad cultural y de asentamiento. Para ello se va a hacer hincapié en el asentamiento de la periferia y, sobre todo, su relación con el de la penillanura. En este sentido, la prioridad va a ser intentar entender el porqué de la diversidad entre yacimientos, en su día agrupados en tipologías y facies. De hecho, como veremos, aún se discute la razón de ser de las motillas, verdaderas excepciones a un modelo de asentamiento mayoritariamente en altura.

Como vienen mostrando los recientes estudios climáticos y de población, La Mancha se encuentra sometida a cambios que pueden afectar a sus sistemas productivos y de organización social (Hinz et al. 2019). Esto debió generar en su momento la alternancia de períodos de abundancia, que llevaron consigo un posible aumento de población, con momentos de carestía, que pudieron derivar en desplazamientos a zonas periféricas más favorables.

Determinar el papel de territorios periféricos como los Montes de Toledo es una de las claves para comprender la diferente configuración territorial y de asentamiento. No olvidemos que las comarcas limítrofes que conforman La Mancha tienen señas de identidad propia. La supuesta independencia viene dada tanto por condicionantes geográficos como medioambientales que, a su vez, repercutirían en la forma de vida, subsistencia, relación con su entorno y, a un nivel que desconocemos, en las representaciones simbólicas o incluso en la lengua.

\section{APUNTES SOBRE CRONOLOGÍA Y ASENTA- MIENTO}

Con las limitaciones que genera la escasez de series de radiocarbono, la densidad de la población en amplias zonas de la submeseta sur a lo largo del II milenio ha quedado demostrada con la enorme dispersión de yacimientos, gracias a la publicación de numerosos trabajos 
de investigación que viene a cubrir la práctica totalidad de su superficie (Fernández Posse y Martín 1991; Pereira Sieso 2007; Martínez Peñarroya 2012; Balsera Nieto 2017). El resultado es la constatación de un incremento de población más o menos continuo en el interior de la Meseta, siendo La Mancha la comarca mejor estudiada, con un desarrollo cultural independiente al de otras regiones (Fernández Miranda y Carrobles Santos 1994).

Pese a que tanto el Bronce de La Mancha como El Argar y el Bronce Valenciano son contemporáneos (Martín et al. 1993: 25), siempre han existido zonas nucleares y otras de contacto receptoras de influencias externas como así lo reflejan actividades comerciales de diferente tipo, con el marfil o el metal como principales materias primas (Martín et al. 1993; Fernández Miranda et al. 1996). Determinar el grado en el que unas regiones influyen sobre otras es una asignatura pendiente que deberá ser resuelta en un futuro (Tarradell 1965; Gil Mascarell 1985; 1995; Almagro Gorbea 1997; Abarquero Moras y Delibes de Castro 1997). Ya nadie cuestiona que el Bronce de La Mancha surge de la evolución interna de los grupos allí establecidos abiertos a múltiples influencias externas, entre ellas las del SE (Blasco Bosqued 1995: 112).

En La Mancha se documenta un área nuclear caracterizada por un patrón de asentamiento y una cultura material homogénea que trasciende a las comarcas limítrofes. La descripción ya clásica del Bronce de La Mancha advertía una tipología de poblados específica para cada entorno, con la división genérica de morras, motillas y castillejos (Nájera 1982; Martínez Navarrete 1988; Ruiz Taboada 1998; Fernández Posse et al. 2008). A estas alturas se asume que dicha diferenciación se debe a un intento de aprovechar de forma eficiente los condicionamientos del medio más que a la confluencia de diferentes facies (Fernández Posse y Martín Morales 2007: 114) y es más compleja de lo que se asumió en un principio.

Como veremos, desconocer qué relación existe realmente entre asentamientos obliga a simplificar sus tipos y reducirlos a dos: yacimientos elevados y en llano. Los primeros localizados por encima del nivel de la penillanura, desde escasos metros a cientos de ellos. En este grupo entrarían morras, castillejos o cualquier otro diseño de yacimiento que ocupa tanto montículos y cimas o laderas elevadas, con una clara intención de control. Los segundos localizados en el llano, desde motillas a fondos de cabaña o cualquier tipo de evidencia de frecuentación.
Estos últimos, lejos de controlar visualmente el territorio son controlados, al menos visualmente, por sus vecinos. Lo que resulta evidente es que conforme nos alejamos del centro de la penillanura, los asentamientos cambian y se adaptan a sus respectivos ecosistemas comarcales, lo que añade gran complejidad y diversidad al repertorio tipológico clásico.

Con respecto a la cronología, la Edad del Bronce de La Mancha se sitúa genéricamente entre el 2250 y el $1500 \mathrm{BC}$ en fechas calibradas (Fernández Posse et al. 2008). En líneas generales su desarrollo se sitúa entre la liquidación del horizonte campaniforme y la consolidación de Cogotas I (Blasco Bosqued 1995: 111).

Aunque existen diferentes propuestas, resulta arriesgado establecer una periodización precisa (Fernández Posse et al. 1996: 126). La muestra de fechas de C14 nos habla de desarrollos independientes de algunos poblados, con coincidencias cronológicas y vacíos. Como ejemplo, la ocupación de la morra de Quintanar se remonta desde antes del 2000 cal BC hasta el 1500 cal BC mientras que la del Acequión entre 2275 cal BC al 1765 cal BC (Fernández Posse et al. 1996; Balsera et al. 2016: 342). El Azuer entre 2200 y 1350 BC estando dividida en diferentes fases con desigual desarrollo: fase I, Bronce Antiguo (2250/2200-2000 BC), fase II, momentos antiguos y medios del Bronce Pleno (2000-1800 BC), fase III Bronce Pleno (1800-1600), fase IV Bronce Tardío (1600-14001350) (López Sáez et al. 2014: 396). Como veremos, pese a contar con un repertorio de fechas en aumento, la asignatura pendiente sigue siendo el determinar la diacronía y sincronía entre la enorme variedad y número de asentamientos que conforman el Bronce de La Mancha (Fernández Posse et al. 2008: 16; Balsera Nieto 2017: 240; Galán Saulnier 2018).

Además de conocer estos datos cronológicos, lo ideal sería poder combinar la información derivada de yacimientos tan distantes como la morra de Quintanar, o las motillas del Azuer y el Acequión, con diferencias significativas entre ambas. Por ejemplo, se debería poder responder a si el aumento de población de la fase III del Azuer tiene su reflejo en otros yacimientos de La Mancha, en una época (entre 1800 y 1600 a.C.) de supuesto crecimiento económico. Del mismo modo, poder establecer la evolución de la fase IV del mismo yacimiento (López Saéz et al. 2014: 398), contemporánea con otras similares como el Acequión en su fase III (Martín Morales et al. 1993) o la morra de Quintanar en su fase II, esta última con evidencias de estar construyendo en ese 
momento el anillo exterior de muralla (Martín Morales 1973: 72). La falta de correspondencia de fechas entre diferentes yacimientos no sólo pone de manifiesto la escasa muestra de dataciones de que se dispone (Fernández Posee et al. 1996: 126; IDEarq), sino la necesidad de unificar los datos conocidos con el fin de detectar cambios en el asentamiento y en la subsistencia a nivel macro territorial. Con ello, se podría empezar a hablar bien de sedentarismo, producto de épocas de bonanza, bien de movilidad, consecuencia de períodos de escasez u otros. Quizá el proceso de poblamiento de la periferia haya que buscarlo entre estos motivos. Tampoco queda claro cuando y por qué se abandonan los yacimientos de la Edad del Bronce en La Mancha incluida su periferia y la causa por la que algunos de ellos se vuelven a ocupar ya bien entrada la Edad del Hierro (Ruiz Taboada 1998) más allá de su prominencia geográfica.

La identificación de estas fases no hace más que recordarnos lo poco que conocemos de la evolución de esta sociedad asentada en los llanos de La Mancha. Cuando tratamos de caracterizar la ocupación surge el problema de la escasa entidad de los asentamientos, recintos pequeños que agruparían a grupos reducidos que rara vez superarían la centena (Fernández Posse et al. 1996). Estos poblados guardarían entre sí distancia suficiente para que su mutua "competencia" haya mantenido cierto equilibrio (Fernández Posse y Martín Morales 2007: 112). De esta forma, la caracterización del asentamiento viene a ser uno de los principales problemas para comprender su propio desarrollo. No todos los poblados debieron ser contemporáneos o, al menos, funcionaron de forma combinada a lo largo del período en esta región. Posiblemente debamos resignarnos al hecho de que, pese a su gran homogeneidad, los asentamientos tan sólo son una fotografía de un grupo de gente, en un tiempo y un territorio determinado. Sin la certeza de los momentos de ocupación y abandono de estos pequeños asentamientos es muy complicado comprender el desarrollo de la Edad del Bronce en esta zona más allá de las hipótesis formuladas de manera reiterada. Esta falta de datos impide pensar que el poblamiento de la periferia es producto del éxodo que se produce en la penillanura de La Mancha, consecuencia de la dureza del medio en momentos de crisis. Como veremos, la existencia de estos posibles desplazamientos no afecta al hecho de que estas zonas debieron contar con una ocupación permanente cuyo origen y desarrollo es clave para entender el conjunto del Bronce de La Mancha.

A la vista de los datos provenientes de la prospección parece que esta homogeneidad aparente del asentamiento no lo es tal, encontrándonos con una variabilidad en

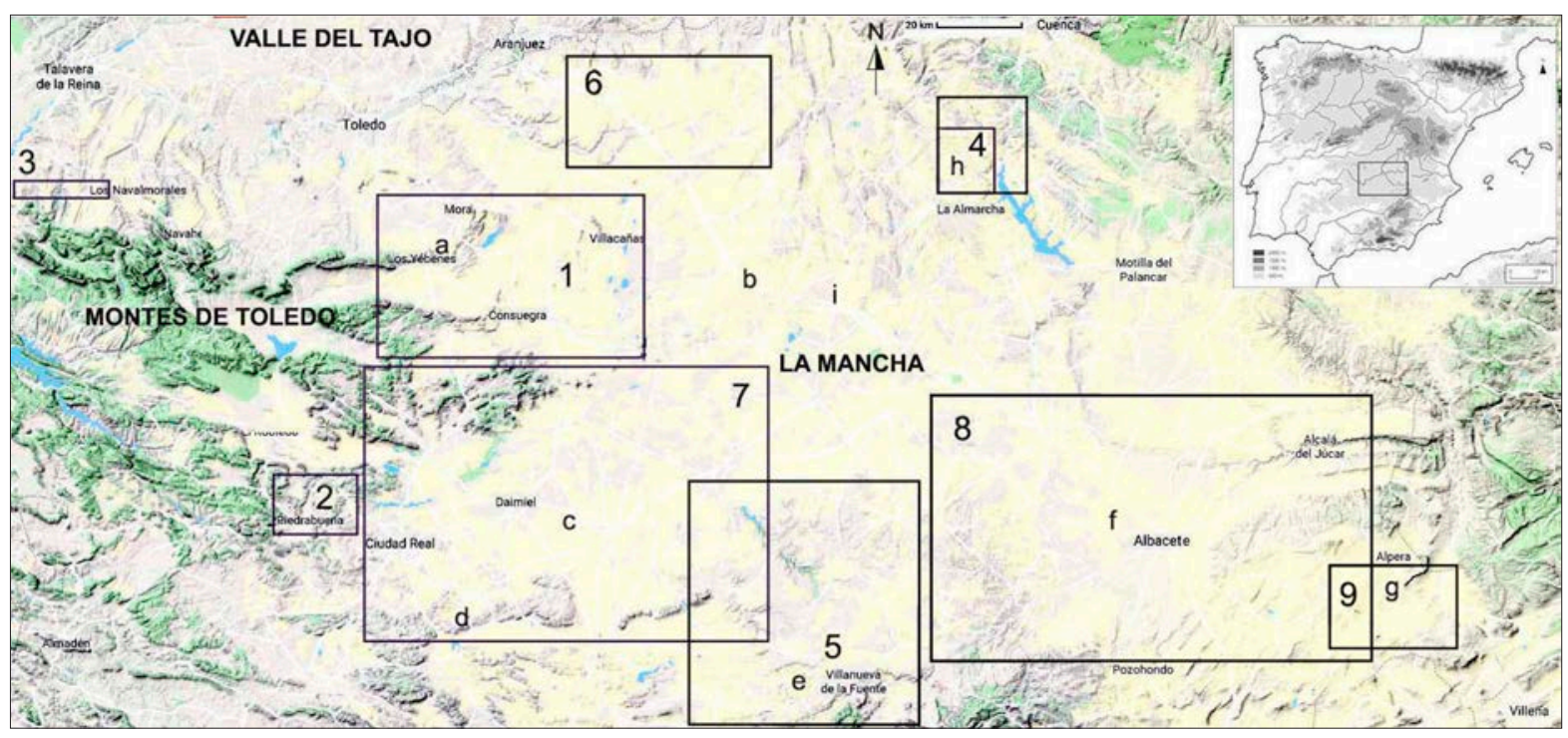

Fig. 1: Principales áreas de investigación y yacimientos mencionados en el texto (Google (C): 1. Montes de Toledo, sector nororiental; 2. Montes de Toledo, sector oriental; 3. Montes de Toledo, sector noroccidental; 4. La Mancha, Alcarria y serranía, Cuenca; 5. Campo de Montiel; 6. Mesa de Ocaña; 7. La Mancha occidental; 8. La Mancha oriental; 9. Corredor de Almansa; a. Montón de Trigo (Toledo); b. Motilla del Morrión (Toledo); c. Motilla del Azuer (Ciudad Real); d. La Encantada (Ciudad Real); e. Castillejo del Bonete (Ciudad Real); f. Motilla del Acequión (Albacete); g. Los Cuchillos (Albacete); h. El Recuenco (Cuenca); i. Motilla del Pedernoso (Cuenca). 
tamaños, estructura interna y morfología, en un territorio ocupado de forma irregular (Fernández Posse et al. 1996: 113). Después de varias décadas se admite que lejos de existir un modelo de asentamiento cohesionado, su heterogeneidad responde a una adaptación al medio geográfico en el que se encuentran, tesis defendida en su momento por Martínez Navarrete (1988). Ya no parecen tener cabida, al menos con los actuales datos, aquellas teorías que defendían una distribución jerárquica del asentamiento con la consiguiente asunción de un territorio cohesionado que incidía directamente en la forma de vida de sus habitantes (Hernández Pérez y Simón García 1994; Gilman 1995).

La cuestión sigue siendo tratar de determinar las causas del por qué de este asentamiento, más que únicamente sus consecuencias. La investigación reciente ha vuelto a fijar su atención tanto en las fluctuaciones del clima a lo largo del II milenio y su relación con una posible explotación de acuíferos como en el mundo funerario. Condiciones extremas de aridez se han documentado en la fase II de la motilla del Azuer entre 2000 y 1800 BC relacionado con el evento climático 4.2. ka cal BP entre el 2350 y el 1850 cal BC (López Sáez et al. 2014: 412; Benítez de Lugo Enrich y Mejías Moreno 2016; Blanco González et al. 2018). Un segundo factor añadido lo encontramos en el posible carácter funerario de alguno de los yacimientos como Castillejo del Bonete, en los que disciplinas como la arqueoastronomía empiezan a ser habituales en la interpretación (Benítez de Lugo Enrich 2018: 163), yacimiento por cierto no exento de polémica (Galán Saulnier 2018).

Como veremos, la periferia es una de las claves para avanzar en el conocimiento de la Edad del Bronce. Dicha periferia la forman comarcas tan dispares como los Montes de Toledo, los campos de Calatrava y Montiel, las sierras de Alcaraz y Segura, el campo de Hellín, el corredor de Almansa, la Manchuela, tierra de Alarcón (Panadero Moya y Pillet Capdepón 1999), o la mesa de Ocaña. Los Montes de Toledo ilustran esta diversidad en donde, de una parte, se aprecia cierta continuidad con respecto a los desarrollos culturales propios del Bronce de La Mancha, al tiempo que difiere en alguno de sus estándares (Ruiz Taboada 1998). Una evolución similar la podemos encontrar en el resto de zonas limítrofes como la mesa de Ocaña o el propio valle del Tajo (Carrobles Santos y Ruiz Taboada 2002), la serranía de Cuenca (Díaz Andreu 1994) o el campo de Montiel (Ocaña Carretón 2002; Romera y Moreno 2015) por citar algún ejemplo (fig. 1).
Por último, la ocupación prehistórica de los montes de Toledo se ve condicionada tanto por el valle del Tajo al $\mathrm{N}$ y O como La Mancha al E. Determinar el grado de influencia de ambos territorios en la configuración del patrón de asentamiento en esta cadena montañosa hoy sigue siendo una incógnita. Mientras la investigación en el valle medio del Tajo demanda proyectos de investigación que articulen los numerosos datos existentes sobre yacimientos de la Edad del Bronce recogidos en las cartas arqueológicas, La Mancha sigue siendo vista como el principal transmisor de influencias, en parte condicionada por su cercanía a otras regiones como Andalucía oriental y Murcia, cultural y cronológicamente relacionadas con El Argar y el sector central de la costa E (Almagro Gorbea 1988; Fernández Posse et al. 1996; 2008: 14; Bernabeu et al. 2018).

\section{LOS MONTES DE TOLEDO Y SU RELACIÓN CON LA MANCHA}

Esta orografía se distribuye a lo largo de la zona suroccidental de la provincia de Toledo y la noroccidental de Ciudad Real. La cadena montañosa está orientada de E a O, y ocupa una superficie de $5000 \mathrm{~km}^{2}$, entre los valles del Tajo y Guadiana, dividiendo la submeseta sur. Sus límites geográficos se fijan en la meseta cristalina de Toledo y las mesas de raña de la comarca de Talavera de la Reina al N, el río Guadiana y el Campo de Calatrava al $\mathrm{S}$, la extensa llanura manchega al E, y la sierra de Altamira al O. El sistema cuenta con un rango altitudinal que oscila entre los 900 y 1300 msnm con múltiples estribaciones que difuminan sus límites (López Sáez et al. 2019). El hecho de que estas estribaciones se adentren en la penillanura de La Mancha impide establecer un límite geográfico claro, lo que indirectamente dificulta caracterizar culturalmente el territorio. Como veremos, esta es una de las razones principales por la que los poblados de la Edad del Bronce de estas sierras comparten tipologías similares a los de La Mancha, aunque su denominador común es tanto la altitud a la que se encuentra con respecto al llano como su escasa superficie. La dificultad de relacionar ambos territorios se incrementa al considerar la enorme distancia que existe entre la propia penillanura y cualquiera de las regiones limítrofes que la componen.

El modelo de asentamiento de la vertiente oriental de los Montes de Toledo durante la Edad del Bronce se conoce por diferentes estudios desarrollados en las décadas de los 80 y 90 del siglo pasado (López Fernández 1990; 
Ruiz Taboada 1998; Molina et al. 2005). La viabilidad de este modelo viene dada por su gran similitud con el asentimiento documentado en La Mancha. De hecho, siempre se ha dado por supuesto que este poblamiento periférico no difiere culturalmente del localizado en la penillanura. Como veremos, esta generalización ha obviado la existencia de diferencias sustanciales lo que, a su vez, ha impedido conocer su verdadero papel en el desarrollo de la Edad del Bronce de La Mancha.

La historia de la investigación de la Edad del Bronce en La Mancha está ampliamente tratada en la bibliografía y, en mayor medida, ha consistido en esa arqueología de asentamientos que antes mencionábamos (Fernández Posse et al. 2008: 14). A lo largo de los últimos 40 años son numerosos los equipos que han trabajado en la zona (fig. 1). Entre ellos destacan la Universidad de Granada cuyo yacimiento insignia es la motilla del Azuer, en plenas lagunas de Daimiel, Ciudad Real (Molina et al. 2005; López Sáez et al. 2014). El equipo dirigido por Manuel Fernández Miranda en La Mancha oriental, con la motilla del Acequión en Albacete también como referente (Martín et al. 1993) y estudios espaciales como los desarrollados en La Mancha nororiental (Díaz Andreu 1994) y noroccidental (Ruiz Taboada 1998). Otras prospecciones también se han llevado a cabo en la comarca de Montiel (Romera y Moreno 2015) o el corredor de Almansa (Simón García 1987; Hernández Pérez y Simón García 1994), junto con excavaciones de largo recorrido entre las que destacan el cerro de la Encantada, en Ciudad Real (Sánchez Meseguer y Galán 2004), el Castillejo del Bonete (Benítez de Lugo 2011; 2018), el Recuenco (Díaz Andreu 1994) o el cerro de Los Cuchillos (Hernández Pérez et al. 1994), por citar los más representativos. Este último, dependiente de la Universidad de Alicante, es clave a la hora de conocer las dinámicas de contacto entre La Mancha y la costa E peninsular, en su área central (Jover Maestre et al. 2018) (fig. 1, g). Como veremos, esta excesiva zonificación y ausencia de cohesión entre proyectos ha derivado en la falta de consenso sobre el origen y desarrollo de la Edad del Bronce.

Volviendo a los Montes de Toledo, desconocemos la relación real con La Mancha debido a la escasez de datos de los que se dispone. Lo que resulta evidente es que no es lo mismo vivir en entornos llanos que hacerlo en altura, ni ocupar cerros aislados de la penillanura manchega que ecosistemas de montaña como los Montes de Toledo. En este sentido, tampoco parece acertado emplear en estos entornos periféricos la tipología de asentamientos válida para La Mancha (Ruiz Taboada 1997). Más allá de esta catalogación tipológica clásica, el asentamiento en llano dista mucho de poder ser equiparado al de altura. Los procesos de formación y desarrollo de los asentamientos en llano responden a unas necesidades diferentes, en parte sometidos a un medio notablemente distinto y a un sistema de explotación de base agrícola. Del mismo modo, la evidencia material/monumental de su existencia es imperceptible salvo en el caso de las motillas. Esta invisibilidad en el territorio genera un importante sesgo de información que poco a poco va saliendo a la luz gracias a la denominada arqueología de gestión (García Huerta y Morales 2004, entre otros). Por el contrario, los yacimientos en altura de las comarcas limítrofes son más visibles y cuentan con el medio como principal aliado, que no sólo les protege y facilita su subsistencia sino que los mantiene aislados. Este supuesto aislamiento les confiere una sensación de seguridad que difícilmente comparten los asentamientos de la penillanura.

Pese a la trascendencia geográfica y humana de los Montes de Toledo, nunca ha existido un especial interés en profundizar en ellos. Jiménez de Gregorio (1970; 2001) es uno de los primeros en sistematizar la frecuentación histórica en su sector occidental. Estos estudios se apoyan en los formularios que en su momento encargan tanto el Cardenal Lorenzana como Felipe II sobre el conjunto de pueblos que conforman estas y otras comarcas del centro peninsular (Ruiz Taboada 1993). Aunque no existe una información específica sobre la ocupación prehistórica de estos montes, a finales de la década de los 80 del siglo pasado López Fernández desarrolla un interesante estudio del patrón de asentamiento durante la Edad del Bronce en un pequeño sector de las estribaciones meridionales, en la actual provincia de Ciudad Real (López Fernández 1990), complementado por Molina et al. (2005) en relación con La Mancha occidental y yacimientos específicos como la motilla del Azuer. A este estudio le siguen otros como los de sus límites nororiental (Ruiz Taboada 1998), noroccidental (Carrobles Santos y Méndez Cabeza 1991) (figs. 1 y 2) y occidental (Urbina et al. 1994; Sánchez Hidalgo et al. 2010). Estos trabajos, en mayor o menor medida, identifican un mismo tipo de asentamiento en altura en las estribaciones de los montes, en torno al comienzo del segundo milenio a.C. Por desgracia, a fecha de hoy desconocemos el modelo de ocupación de los sectores centrales y orientales de los montes (fig. 1). 
Fig. 2: Dispersión de poblados en altura con superficie conocida en las sierras que forman el límite nororiental de los Montes de Toledo y su desarrollo por la penillanura (zona 1, fig. 1). Montes de Toledo: 1. Lituero; 5. Montón de Trigo; 6. Frontón oeste; 13. Aljibe de la Cabra; 14. Cerro Labor; 16. Valhondo; 17. La Mina; 23. Las Pedreras; 24. Cabezuela; 26. Candelaria sur; 27. Aljibe. La Mancha (Toledo): 39. Buenos Vinos; 40. Estanque; 42. Atalaya de Yeguas; 43. Silos de la Atalaya; 47. Atalaya II; 49. Aljibe Manzano; 50. Romeral.

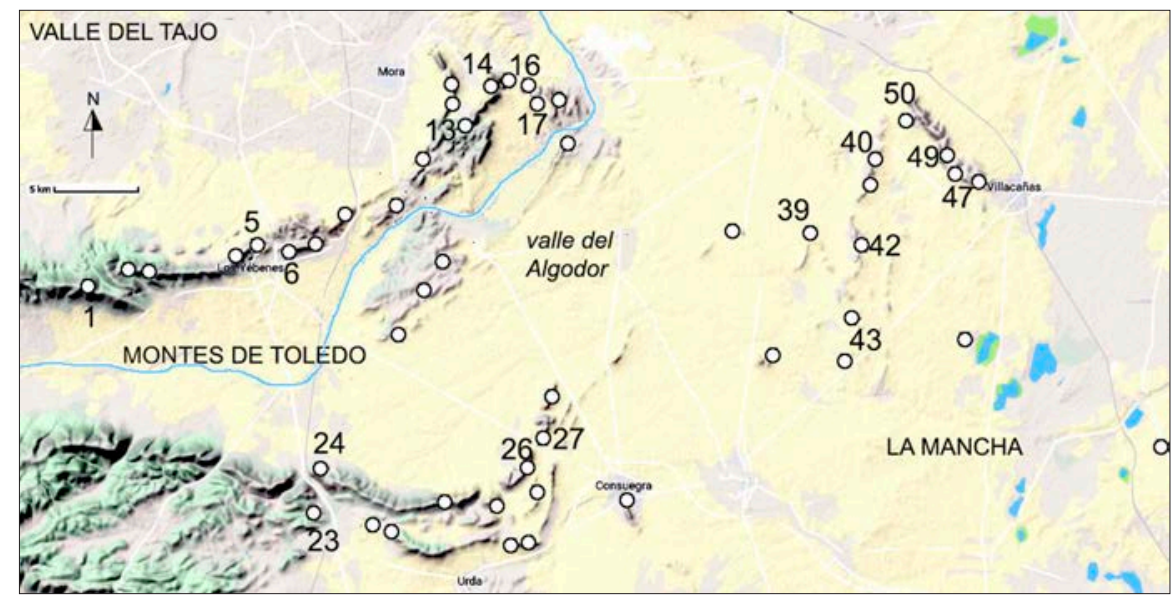

Los Montes de Toledo son una comarca autónoma y con identidad propia aunque sometida a influencias externas dependiendo del territorio con el que limita. Así, el sector occidental está condicionado por el río Tajo como principal vía de penetración atlántica. Estas influencias tienen su reflejo material no sólo en los monumentos megalíticos como los dólmenes de Azután y La Estrella (Bueno Ramírez et al. 2007; 2010), sino en los poblados en altura de supuesta tradición calcolítica y del bronce en la comarca de La Jara (Carrobles Santos y Méndez Cabeza 1991)(fig. 1,3) y sierra de Altamira (Sánchez Hidalgo et al.2010) o pervivencias orientalizantes como la tumba del Carpio de Tajo (Pereira Sieso 2012). En el conjunto de los montes existen representaciones rupestres postpaleolíticas como en de la comarca de La Jara (Jordá Pardo et al. 1999) o Los Yébenes (Ruiz Taboada 1998), que hablan de una frecuentación prehistórica en toda la zona monteña.

Este patrón de asentamiento ha debido estar siempre sometido a múltiples influencias externas, con dos grandes ejes de comunicación que durante milenios han ejercido de verdaderas autopistas culturales como son los valles del Tajo y del Guadiana (Balsera Nieto 2017: 247). Como hemos mencionado, un ecosistema de montaña lleva implícito una amplia independencia con respecto a otros territorios. El problema radica en determinar el grado de dependencia de los unos frente a los otros. En el caso de La Mancha, la especial distribución de estos territorios limítrofes montañosos, que ejercen de barrera natural contrasta con la existencia de corredores naturales que la relacionan con otras comarcas más alejadas. Entre ellos el ya mencionado valle del Tajo, que posee una comunicación directa con el sector $\mathrm{N}$ de La Mancha a través del valle del Algodor, cuyo cauce nace en las estribaciones nororientales (fig. 1, 1 y 2). Algo similar ocurre con el sector SE, siendo el corredor de Almansa la salida natural al sector central de la costa mediterránea (fig. 1, e).

Por último, la subsistencia para las poblaciones monteñas no debió diferir mucho de la que ha llegado hasta nuestros días y, aunque en menor medida, en la actualidad ha perdurado hasta bien entrado el s. XX. Los encinares, con pies de quejigo y alcornoque, junto con los jarales, son las principales formaciones vegetales que caracterizan los Montes de Toledo. Los robles o rebollos, que están presentes en las partes más altas y umbrías, han dado lugar a numerosos topónimos de sus núcleos de población. Los cultivos, escasos, pobres y distribuidos en pequeñas propiedades, son de cereales y olivares. Por último, actividades residuales como la apicultura, o en su momento la recolección y consumo de bellotas (García Gómez et al. 2020), se complementa con el ganado caprino y ovino (López Sáez et al. 2019: 46).

Es indudable que regiones periféricas como los Montes de Toledo son clave para entender el desarrollo de la Edad del Bronce en La Mancha. La cuestión es averiguar el papel de la periferia en este desarrollo y establecer los procesos de aculturación en sus más de 700 años de existencia. Pese al indudable avance de estas últimas décadas, aún falta por determinar cómo se articula este poblamiento en relación con la penillanura e identificar los movimientos de población en sus diferentes fases de desarrollo. La mayoría de modelos aplicados no suelen reparar en lo dilatado de este proceso, a menudo entendido de manera lineal y sincrónica cuando el registro material conocido apunta a lo contrario. 


\section{LA PERIFERIA DE LA MANCHA COMO UN FACTOR A TENER EN CUENTA}

A estas alturas nadie duda de la existencia de una ocupación calcolítica previa en La Mancha (Fernández Posse et al. 2001; Galán Saulnier 2016; 2018) aunque no es hasta la Edad del Bronce cuando se generaliza el asentamiento en toda la zona. Hemos visto como las dataciones de radiocarbono sugieren una frecuentación continua aunque no necesariamente sincrónica de la penillanura. Lo limitado de estas series impide generar modelos de poblamiento. Dejando a un lado cuestiones funerarias que nos alejarían del propósito del artículo, contamos con la certeza de la continuidad tipológica entre centro y periferia en cuanto al diseño del asentamiento, un registro material similar y un modelo de explotación económica adaptado a cada uno de los medios. Como veremos a continuación, ninguno de estos tres marcadores sirve para definir el Bronce de La Mancha.

El primero de ellos es el asentamiento. En este apartado analizamos de forma comparada tanto el del llano como el de la periferia, tomando para esta última como referencia el oriente de los Montes de Toledo. Se parte de la base de que la falta de excavaciones arqueológicas en la periferia impide establecer cualquier comparación genérica con el conjunto de La Mancha, lo que obliga a actuar con la debida cautela. En contraprestación, se tiene constancia de una ocupación humana de las sierras plenamente consolidada similar, en líneas generales, a la de la penillanura.

Los Montes de Toledo no sólo son comarca independiente, sino que forman parte de uno de los límites de La Mancha, entendidos como prolongación de su territorio

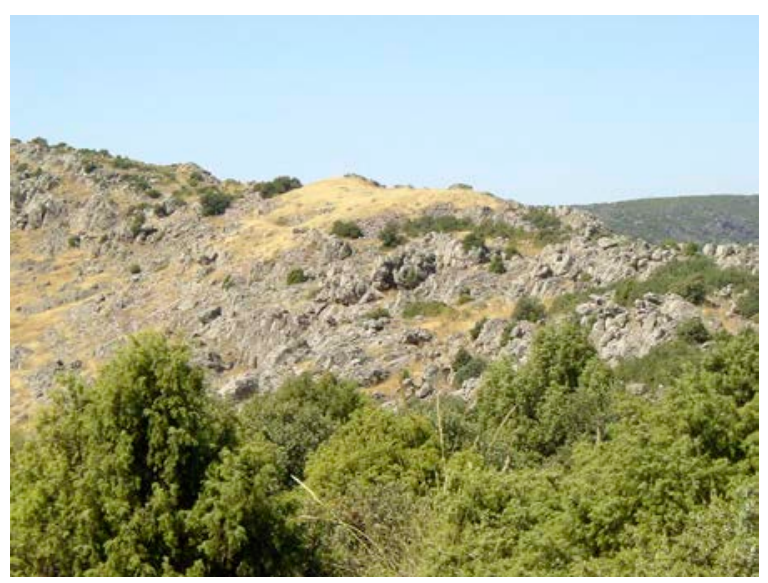

Fig. 3: Yacimiento Montón de Trigo, Los Yébenes (Toledo). (fig. 2). Desconocemos el momento en el que estas sierras fueron habitadas aunque la potencia de los yacimientos sugiere una ocupación en el tiempo. Aquí, el asentamiento se rige únicamente por criterios de accesibilidad y visibilidad: las fuertes pendientes, lo escarpado y la tupida vegetación forman una barrera natural que confiere una especial protección al poblado mientras que la altitud favorece el control del territorio circundante (figs. 2 y 3). La superficie de estos poblados suele ser bastante reducida adaptada a estas condiciones extremas (fig. 4). Esta caracterización se pierde conforme descendemos en altura y nos aproximamos a La Mancha. En este caso, los asentamientos poseen mayor superficie de ocupación cuanto más próximos se encuentran del llano (fig. 2, 5 y 50).

Esto trasladado a números resulta en un modelo de asentamiento condicionado tanto por la altitud, entre los 650 y los 1200 msnm con un desnivel medio de 66,62 m sobre el llano circundante, como por la superficie de ocupación (Ruiz Taboada 1998). El total de la muestra se compone de 50 yacimientos, localizados tanto en plena montaña como en la periferia en contacto con la Mancha (fig. 2). En 18 de los cuales se conserva suficiente depósito arqueológico y material en superficie como para considerarlos estables. De ellos contamos con la planta y la superficie de habitación (fig. 4). El resto apenas conserva depósito arqueológico y poco material en superficie, lo que en su momento fue interpretado como asentamiento estacional o secundario.

De estos 18, Montón de Trigo (5) y el Romeral (50) son los de mayor tamaño, en torno a los $1600 \mathrm{~m}^{2}$, situados a escasa distancia del llano y relativamente accesibles. Cinco se agrupan en torno a unos determinados valores de desnivel y superficie destacando del resto; 50 a 100 metros de desnivel medio, y 1100 y $1300 \mathrm{~m}^{2}$ de superficie de ocupación: Montón de Trigo (5), Frontón oeste (6), Frontón este (7), cerro Labor (14), y Guillema este (33). El resto de yacimientos se agrupan en torno a los 50 $\mathrm{m}$ de desnivel y los 100 y los $800 \mathrm{~m}^{2}$ de ocupación. Tres de los cuales tienen un desnivel superior al de la media (74,3 m), que oscila entre los 150 y los $300 \mathrm{~m}$ y se corresponden con Lituero (1), La Olivilla (2) y Los Mártires (3), en terrenos de gran altitud relativa y muy difícil acceso. Por último, los siete yacimientos localizados en La Mancha, salvo Romeral (50), comparten similares parámetros de altitud y superficie, entre 20 y $80 \mathrm{~m}$ de desnivel y 30 y $500 \mathrm{~m}^{2}$ de superficie: (39) Buenos Vinos, (40) Estanque, (42) Atalaya Yeguas, (43) Silos Atalaya, (47) Atalaya II y (49) Aljibe Manzano (figs. 2 y 4). 


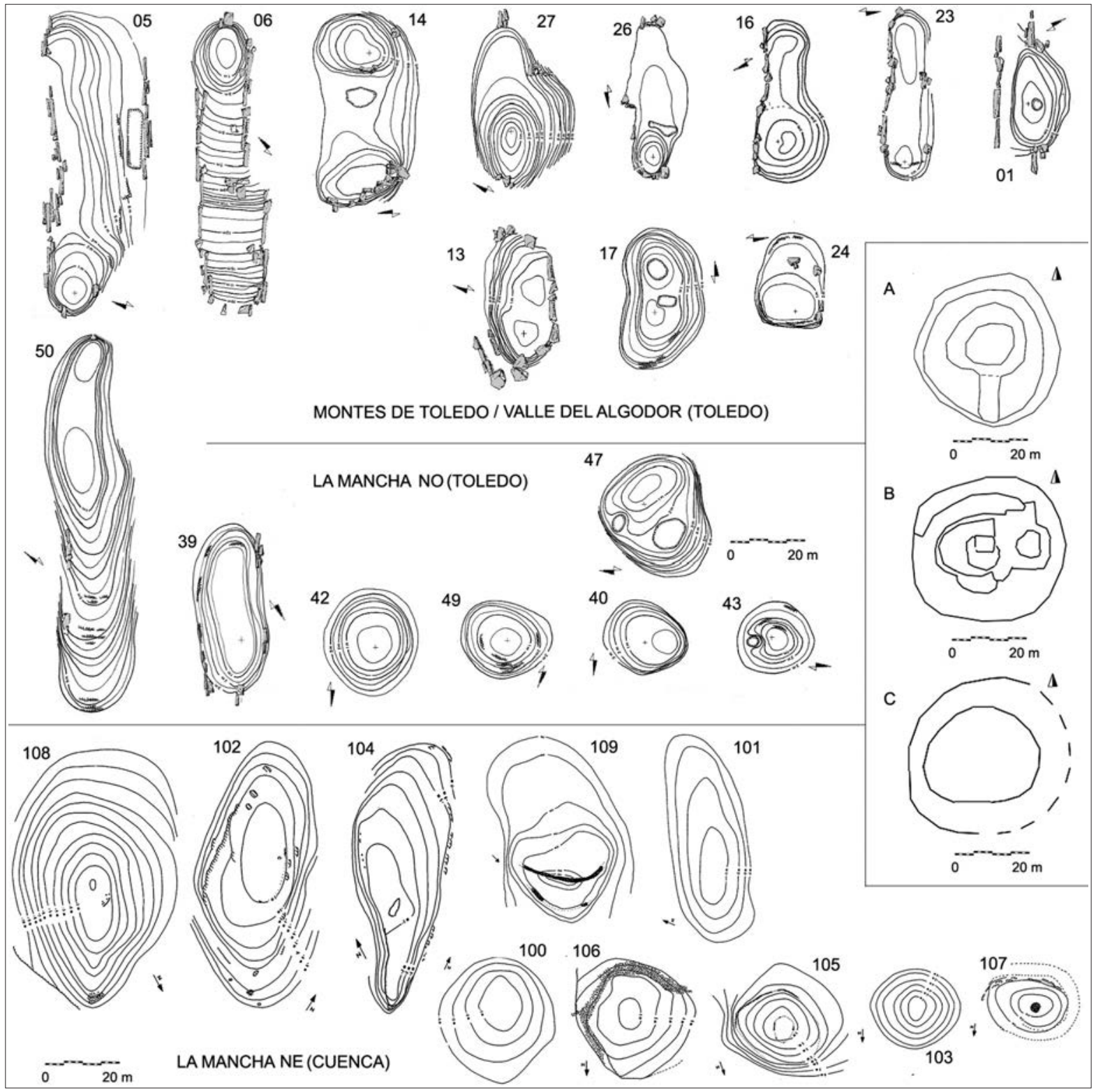

Fig. 4: Comparativa de las plantas de los diferentes poblados localizados tanto en las estribaciones nororientales de los Montes de Toledo y la serranía de Cuenca en relación con La Mancha. Montes de Toledo: 01. Lituero; 05. Montón de Trigo; 06. Frontón oeste; 13. Aljibe de la Cabra; 14. Cerro Labor; 16. Valhondo; 17. La Mina; 23. Las Pedreras; 24. Cabezuela. 26. Candelaria sur; 27. Aljibe. La Mancha (Toledo); 39. Buenos Vinos; 40. Estanque; 42. Atalaya de Yeguas; 43. Silos de la Atalaya; 47. Atalaya II; 49. Aljibe Manzano; 50. Romeral (según Ruiz Taboada, 1998). La Mancha (Cuenca): 100. La Cabecilla Aguda; 101. La cabeza de Santa María; 102. La casa de la Vega; 103. El cerrillo Agudo; 104. El cerro Pelado; 105. El Gurugú; 106. La morrota de los Cotos; 107. La Peñuela; 108. El puntal del Águila; 109. El Recuenco (según Díaz Andreu, 1994); A. Motilla del Morrión (Toledo); B. Motilla del Azuer (Ciudad Real); C. Motilla del Acequión (Albacete). Fotointrepretado de Google.

Esta especial configuración del asentamiento viene dada por la geología de los Montes de Toledo, con un desarrollo lineal y uniforme en el afloramiento de sus estratos. Esto, a su vez, permite aprovechar los crestones y salientes de las cimas como delimitación externa del espacio habitado (fig. 2). La mayoría de estos poblados aprovecha esta circunstancia y definen su interior mediante muros perimetrales (fig. 4). Los yacimientos se sirven de 
las materias primas que les brinda el entorno: barro, madera y pequeño mampuesto de roca de cuarcítica, natural de las propias sierras (canchales o pedrizas). En los casos de fuerte pendiente, es común encontrar muros bancales que permiten aterrazar el asentamiento. Con respecto a los muros perimetrales, la funcionalidad siempre ha sido objeto de debate, en unos casos considerados como mecanismos de defensa ante posibles momentos de inestabilidad (Nájera et al. 2012), en otros como cierre simbólico del espacio habitado, que hace las veces de protección frente a las inclemencias meteorológicas y de soporte estructural a las construcciones interiores (Ruiz Taboada 1997). La especial naturaleza de los asentamientos apunta más a un uso funcional y simbólico de estos muros. Esto es extrapolable al resto de La Mancha aunque no se descarta que en momentos puntuales de inestabilidad pudiera ser defensivo.

La elección del asentamiento se ve también condicionada por la cercanía a fuentes o cursos de agua en sus inmediaciones. Muchas veces encontramos diaclasas naturales en el interior o exterior de los yacimientos que almacenan naturalmente el agua de lluvia (Ruiz Taboada 1998). El hecho de que estas diaclasas se localicen en el exterior del perímetro habitado vuelve a poner en duda el carácter defensivo de estos asentamientos, frente a lo sugerido para las motillas. La existencia de cisternas naturales ha tenido reflejo en la toponimia local con denominaciones como sierras o montes de los aljibes.

Un último aspecto a tener en cuenta es la amplia visibilidad. Ello permite el control tanto de otros poblados como de las zonas de aprovisionamiento de recursos. Los estudios efectuados sobre un radio de 1 y $2 \mathrm{~km}$ demuestran que el principal interés estratégico se centra en puertos y pasos naturales cercanos y la conexión visual con el resto de sitios (Ruiz Taboada 1998). Desde estos yacimientos se domina un vasto y poblado territorio. Para entender estas conexiones, contamos con evidencias materiales indirectas como el papel del fuego en la comunicación visual entre asentamientos. Los hogares debían ejercer de elemento de cohesión comarcal puesto que el humo era perceptible desde decenas de kilómetros. Esto permite imaginar como sería el ambiente del momento, con un patrón de asentamiento nuclearizado, en donde el humo sería el reflejo de una ocupación dispersa aunque conectada entre sí. En este sentido, la seguridad que ofrece el ocultamiento por la topografía contrasta con la visibilidad que ofrece el humo. Como ya hemos visto con el suministro de agua, este dato vuelve a poner en cuestión la intención estrictamente defensiva de los asentamientos.
Esta caracterización del poblamiento periférico en altura bien pudiera ser extrapolable a lo que sucede con otros límites montañosos como al occidente de la serranía de Cuenca y la Alcarria (Díaz Andreu 1994), cuyo patrón de asentamiento en límite con La Mancha resulta similar al documentado en el sector oriental de los Montes de Toledo (fig. 4). El único elemento diferenciador entre ambos modelos es el mayor tamaño medio de los poblados de las estribaciones de la serranía conquense, debido posiblemente a una topografía menos adversa.

La cuestión pendiente es ver hasta que punto esta periferia puede ser considerada, en igualdad de condiciones, Bronce de La Mancha. Hemos visto como las zonas altas limítrofes de montaña soportan un poblamiento muy bien definido, y con sus propias características, aunque inspirado en alguno de los elementos que caracterizan los yacimientos del llano. Con esta salvedad, estos asentamientos pueden ser considerados como reflejo de aquellos localizados en el interior de la penillanura, aunque estos últimos difieren tanto en tamaño, tipología o disponibilidad de recursos (Gilman et al. 2000).

Lo que parece común tanto para La Mancha como para su periferia es la preferencia por lugares elevados para el asentamiento. Esto contrasta con un tipo de poblado diferente y minoritario que, no obstante, es el emblema del Bronce de La Mancha: la motilla. La trascendencia de estos yacimientos viene dada tanto por la perduración en el tiempo como por su arquitectura monumental. Su estructura se compone de uno o varios anillos concéntricos que habilitan diferentes espacios interiores a modo de terraza y que, a su vez, les sirve de protección. Las distintas alturas permiten elevarse unos metros ganando en visibilidad, con una torre o estructura central. La función y emplazamiento varía, pudiendo ocupar tanto lagunas como el Acequión (Albacete, fig. 4, C), humedales como el Azuer (Ciudad Real, fig. 4, B) o zonas inmediatas a cursos de agua como el Morrión (Toledo, fig. 4, A y 5) (Ruiz Taboada 1994).

Pese a la monumentalidad y trascendencia, su número sigue siendo irrelevante si las comparamos con los cientos de asentamientos en alto del interior y la periferia de La Mancha. La superficie tampoco parece ser un factor determinante puesto que, aunque importante, existen otros yacimientos en alto de mayor tamaño (fig. 4). Lo que si parece un elemento diferenciador es su limitación casi exclusiva al oriente de La Mancha (Benítez de Lugo y Mejías Moreno 2016). 
Fig. 5. Imagen aérea de la motilla del Morrión junto al arroyo del Cuadrejón o zanja de la Motilla, El Toboso (Google (C)).

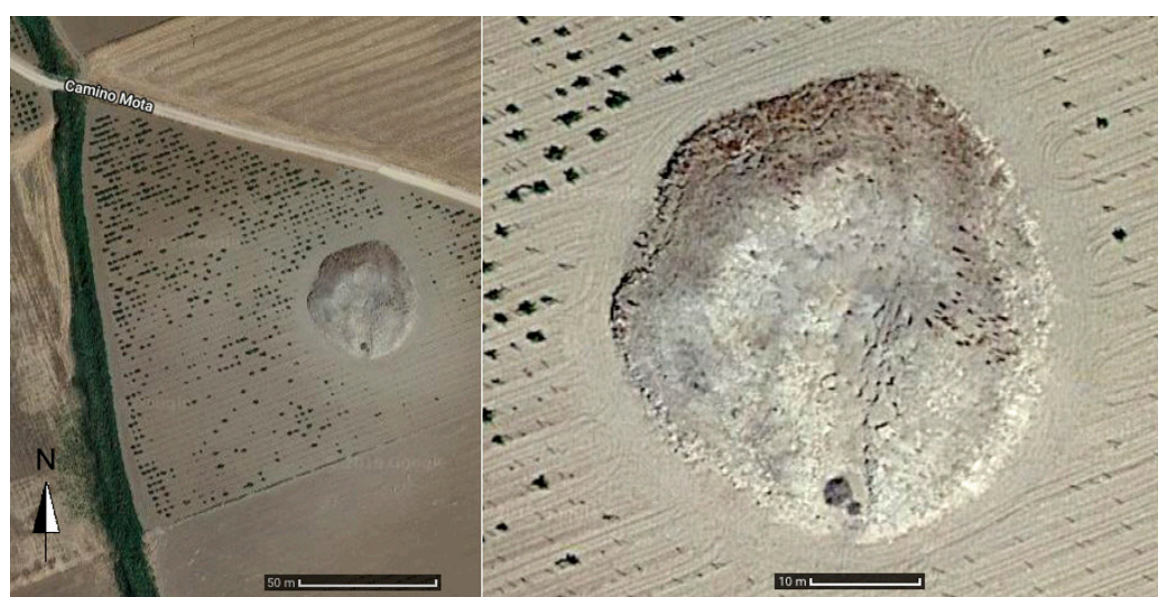

La mayor concentración de motillas se encuentra en la provincia de Ciudad Real (35 motillas, el Azuer entre ellas), siendo residual en las provincias de Albacete (9, el Acequión entre ellas), Toledo (una, el Morrión) y Cuenca (una, el Pedernoso), lo que suman un total de 46 conocidas hasta la fecha (Lenguazco González 2018: 188). Estas dos últimas son las más meridionales de La Mancha (fig. 1). Existen estudios recientes que sintetizan toda la información a este respecto (Benítez de Lugo Enrich 2010; Lenguazco González 2016).

No existe un consenso sobre la función de estos yacimientos, en origen considerados túmulos funerarios o herederos de influencias calcolíticas del SE (Sánchez Jiménez 1948; Martínez Santa-Olalla 1951) aunque tradicionalmente relacionados con el control de recursos estratégicos como el cereal y el agua (Sánchez Meseguer y Galán 2004) o con la ocupación de zonas deprimidas y cursos de agua más o menos estable (Nájera y Molina 2004). Para estos últimos, este tipo de asentamiento se caracteriza por ser contemporáneo a los poblados en altura y formar un sistema político complejo con una importante interdependencia y jerarquización social (Nájera y Molina 2004). En su momento, ya fueron considerados fósiles directores del Bronce de La Mancha (Hervás y Buendía 1899; Estavillo Villaumbrosa 1950; Sánchez Jiménez 1948).

Hoy en día se admite esta relación con el agua, en concreto con los acuíferos 23 y 24, asociados con el núcleo de motillas ciudadrealeñas como representantes de uno de los sistemas de captación de agua subterránea más antiguos de Europa (López Sáez et al. 2014; Benítez de Lugo Enrich y Mejías Moreno 2016). No obstante, también debemos actuar con la debida cautela a la hora de establecer generalizaciones en este sentido (Galán Saulnier 2018: 171).
Los datos conocidos hasta el momento sobre las motillas no hacen otra cosa que poner en evidencia el desconocimiento que se tiene del patrón de asentamiento en La Mancha y, en concreto, del de altura. Además, cuanto más se conoce del funcionamiento interno de las motillas más dudas se generan. La ocupación continua a lo largo de la Edad del Bronce de estas motillas parece responder a la garantía en el abastecimiento de agua, lo que permite el desarrollo de una intensa actividad agrícola (López Sáez et al. 2014). Si se admite la hipótesis de que un evento climático convierte al agua en bien de prestigio en momentos de escasez, cabría preguntarse qué ocurre con el resto de poblados en altura y qué papel juegan estas motillas en los procesos de ocupación tanto del entorno inmediato como de la periferia.

El escaso número de yacimientos excavados ya sean motillas o de otro tipo impide proponer hipótesis alternativas a las ya conocidas. No obstante, la comparativa entre poblados excavados y no, puede ayudar a entender la dinámica de ocupación y del espacio doméstico entre asentamientos. Como ejemplo las motillas del Azuer, excluyendo su contorno, y del Morrión (fig. 4, A y B) muy similares en morfología y separadas entre sí varios cientos de kilómetros. La superficie ocupada se corresponde con un rango de tamaño medio alto con respecto a otros asentamientos (fig. 4). Esto genera una serie de problemas de interpretación que pueden ser extrapolables al conjunto de La Mancha. De una parte, se desconoce la relación cronológica que existe entre las dos motillas y si las fases aplicadas para el Azuer serían válidas para otras motillas como el Morrión. De otra, el aspecto musealizado de la motilla del Azuer (Torres Mas 2015), lejos de facilitar la lectura del yacimiento lo complica. El que 
exista un mayor o menor grado de ocupación del yacimiento no implica una continuidad cultural (Galán Saulnier 2018). La imagen actual que se proyecta no deja de ser una fotografía trucada de un momento concreto en su secular historia, con dificultad de interpretación que ello genera para el visitante. El problema radica en que esa visión fotográfica de un momento determinado es la que viene empleándose para tratar de explicar el Bronce de La Mancha. Esta última reflexión pone de manifiesto la debilidad del método de estudio y la necesidad de generar nuevas alternativas.

El segundo factor coincidente del Bronce de La Mancha era la existencia de un registro material similar, representado mayoritariamente por la cerámica. Este registro es el más abundante y proviene tanto de prospecciones en superficie (Fernández Posse et al. 2008) como de excavaciones (Galán Saulnier 1994). De estas últimas haremos mención a algunas de ellas como las del cerro de La Encantada (Nieto Gallo y Sánchez Meseguer 1980), el Acequión (Martín et al. 1993; Fernández Posse et al. 2007), la motilla del Azuer (Molina et al. 2005; Fernández Martín 2005) o, más recientemente, el castillejo del Bonete (Benítez de Lugo Enrich 2011; 2018). En ellos se describe la existencia de diferentes fases de ocupación, no necesariamente sincrónicas, con una mínima variación en la línea estilística de sus cerámicas.

En el caso de los Montes de Toledo, estas cerámicas son similares a las del resto de La Mancha. Los tipos predominantes son cazuelas carenadas, ollas de almacenamiento, grandes orzas, botellas y cuencos hemisféricos, así como recipientes de base plana y queseras (fig. 6), en donde se combina la homogeneidad de su técnica de fabricación con la línea estilística de la cerámica, simple y repetitiva (Ruiz Taboada 1998). La decoración más común la constituyen digitaciones y ungulaciones en los bordes, cordones, mamelones y asas. La escasa representatividad de la línea estilística de la cerámica dificulta hacer cualquier generalización sobre su funcionalidad y cronología. Estas formas están presentes tanto en La Mancha como en su periferia, lo que permite hablar de la existencia de una extensa red de contactos.

La existencia de contactos está documentada arqueológicamente tanto a nivel local y regional como a larga distancia. A nivel local contamos con análisis de isotopos estables (Balsera et al. 2016), u otros como lámina delgada de molinos encontrados en la superficie de los asentamientos de límite noroccidental de La Mancha o Montes de Toledo (Ruiz Taboada y Montero 2000), con las reservas que genera este tipo de estudios en el conjunto de relaciones sociales (Chapman 2008). Para el resto de materias primas, el metal es el que cuenta con mayor protagonismo (Fernández Miranda et al. 1996) y, en menos medida, la sal (Ruiz Taboada 1998). Por su parte, el marfil demuestra la existencia de un comercio a media o larga distancia, con tipologías y técnicas de extracción estandarizados no sólo en La Mancha sino en la costa mediterránea (Martín et al. 1993: 34; López Padilla 2006; Barciela González 2012: 215). En definitiva, este intercambio podría ser la base para entender la relación entre comunidades y responsable de influencias de índole social y cultural entre ellas.

Por último, con lo que respecta a la explotación de los recursos naturales, el principal inconveniente lo tenemos a la hora de identificar posibles variaciones del ecosistema en los últimos 4000 años. Con lo que respecta a los Montes de Toledo, la vegetación no debió ser la misma que la de la penillanura, con un medio ambiente húmedo y fresco producto de la especial distribución del paisaje montañoso. En la actualidad, la cubierta vegetal no conserva su originario porte forestal ni su densidad, y aparece degradada y sustituida por comunidades de monte bajo y matorral. No obstante, conocemos alguno de sus aprovechamientos gracias a las fuentes latinas que, de manera genérica, hablan de la subsistencia de las poblaciones monteñas. Estrabón en el libro III de su Geografía dedicado a Iberia comenta cómo los montañeses se nutren tres cuartas partes del año de bellotas, que secas y trituradas se muelen para hacer pan el cual puede almacenarse y durar mucho tiempo (Pereira Sieso et al. 2003). En la misma línea, Plinio habla de la bellota como recurso principal en la dieta de estos pueblos, lo que da idea de su importancia.

Pese a lo sugerente de estas afirmaciones, los Montes de Toledo poseen una diversidad natural que permite obtener infinidad de recursos naturales que aseguran la subsistencia de las comunidades de la Edad del Bronce y posteriores y que debieron ser diferentes a los de La Mancha. Además de los bosques, la ganadería debió ser la principal base de la subsistencia. A falta de estudios tafonómicos y análisis de fauna en contextos arqueológicos, contamos con referentes cercanos que pueden ilustrar sobre este tipo de aprovechamiento. El cerro del Bu, a orillas del Tajo y en un entorno de sierra, ilustra un tipo de economía de subsistencia que debió estar también presente en los poblados en altura de los Montes de Toledo. 
Fig. 6: Formas cerámicas características de las estribaciones nororientales de los Montes de Toledo halladas en la superficie de los poblados, según Ruiz Taboada (1998).

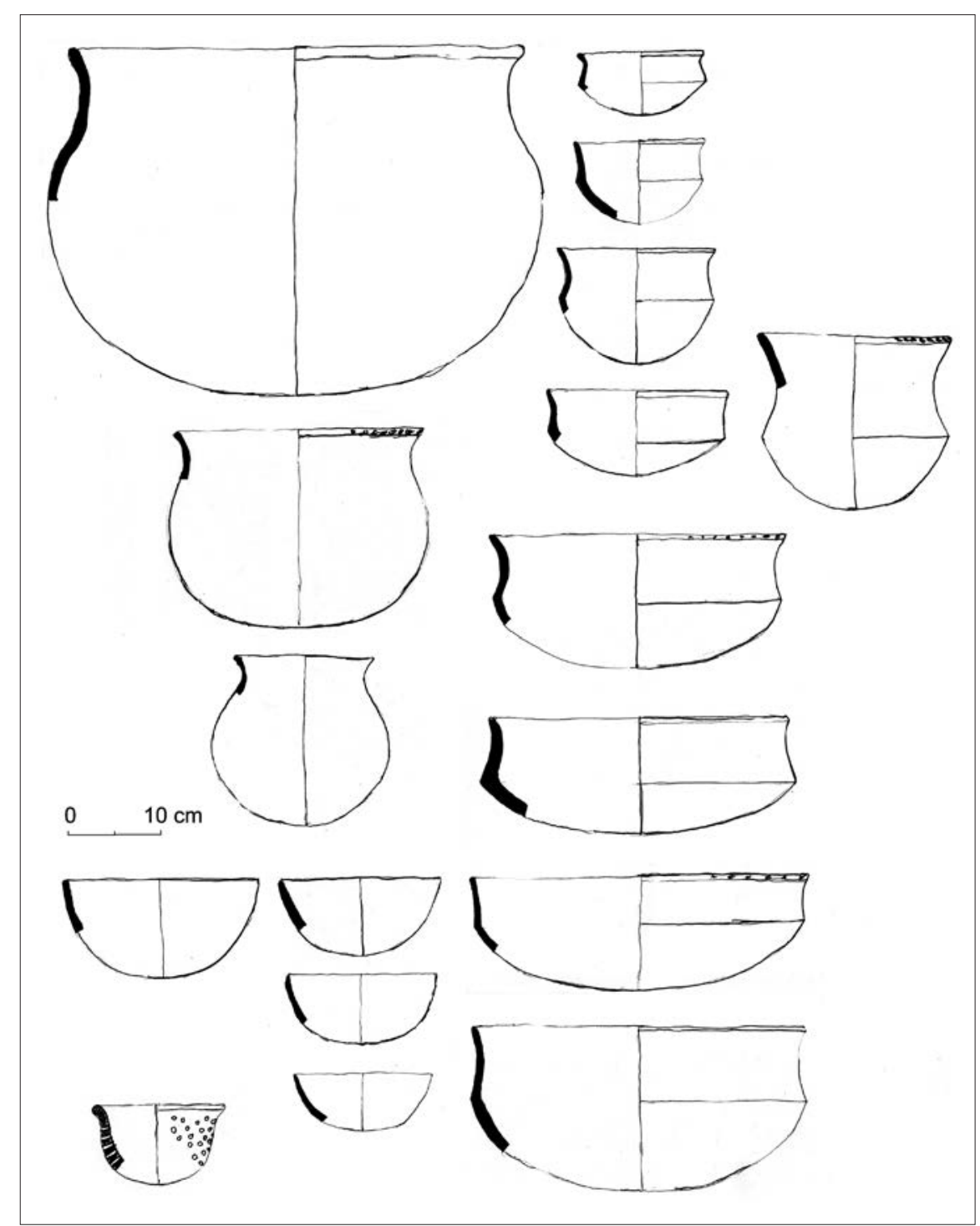

En este yacimiento se ha constatado el empleo creciente de animales de carga y de productos lácteos, con presencia de ovicápridos y ganado bovino, junto con el caballo y el perro, en detrimento del ganado porcino, más típico de las economías agrícolas (Alvaro y Pereira Sieso 1990: 209).

En los Montes de Toledo la ganadería y, sobre todo, la explotación de sus productos secundarios (leche, labor, transporte, lana o abono), debió ser la base de la subsistencia (Ruiz Taboada 1998). La falta de estudios de fauna obliga a buscar otros indicadores arqueológicos de esta actividad. Hasta ahora, la única evidencia material proviene del estudio de la localización de los poblados y del análisis de materiales. Uno de estos materiales bien pudiera ser la presencia en el registro arqueológico de vasos coladores o queseras (fig. 6). La localización de los asentamientos, aprovechando la visibilidad y protección que brindaban las cumbres de las sierras que forman este sistema montañoso, sugiere la existencia de una subsistencia centrada en el aprovechamiento de los recursos ganaderos y del medio boscoso. Es fácil imaginar el desarrollo de una transterminancia de rebaños de ovejas y cabras, similar a la que se practica hoy en día (García Martín 1991: 35; Davidson 1980: 146), aprovechando los frutos del monte, coscoja y quejigo, en alternancia con los pastos de temporada (Ruiz Taboada 1998). 
Por su parte, en La Mancha se mantiene esta tendencia aunque con preferencia, como hemos mencionado, por la agricultura. En este caso, el registro antracológico y polínico en las diferentes fases de la motilla del Azuer ha desvelado la existencia de roble, encina, alcornoque, y de forma menor, el pino (López Saéz et al. 2014: 411). La paleoeconomía de este yacimiento apunta al cultivo de cereal y leguminosas, con presencia de ovicápridos, suidos, bóvidos y équidos. Por su parte. el registro polínico del Acequión apunta a oleáceas, aliso y sauce, junto con herbáceas de los terrenos baldíos. En este último se puede hablar de un sistema mixto de cereales, trigo y cebada (agricultura relativamente intensiva) y ganadería (Fernández Posse y Martín Morales 2007: 115-116), con la explotación de sus productos derivados (Jover Maestre y López Padilla 2013). Por citar otro ejemplo, contamos con los datos provenientes del Recuenco, en donde se ha documentado una agricultura de secano y regadío, documentación de humedales con fines hortícolas y el complemento de la dieta mediante la recolección de frutos silvestres (Rivera et al. 1994).

\section{AISLAMIENTO O CONTACTO}

Cuarenta años de investigación han evidenciado la multiplicidad de teorías y materiales que tratan de definir el denominado Bronce de La Mancha. Las diferencias no sólo provienen de un registro material bastante variado y complejo, sino de la confluencia de otras comarcas limítrofes en la configuración cultural del territorio (Frank 1993; Rowlands et al. 1987). A estas alturas cabe preguntarse si realmente existe un Bronce de La Mancha o, por el contrario, un Bronce de La Mancha y sus comarcas. Pese al escaso protagonismo en la investigación, es evidente el importante papel que debieron jugar estas comarcas periféricas en su desarrollo. Los Montes de Toledo ilustran esta complejidad y muestran el camino para entender tanto el nivel de contacto como de aislamiento de estas comarcas en relación con la penillanura. Un planteamiento similar viene aplicándose en los límites que constituyen la actual Comunidad Valenciana, donde diferentes autores han insistido en la necesidad de profundizar en las unidades territoriales que constituyen las comarcas naturales de esta zona como el método idóneo para explicar las diferencias tipológicas y cronológicas entre yacimientos (Tarradell 1969; Gil Mascarell 1995: 26; Jover Maestre et al. 2019).
Siempre se ha asumido la ausencia de estudios comparados y la falta de datos como los principales lastres de cualquier investigación en La Mancha. Pese al indudable impulso dado por los recientes estudios climáticos y del mundo funerario, el Bronce de La Mancha sigue demandando una visión conjunta que considere las comarcas de la periferia como verdadero motor de desarrollo. Una de las causas de esta indefinición radica en la disparidad de indicadores de validación de hipótesis tanto para el centro como para la periferia de La Mancha. La primera cuenta con indicadores como el modelo de asentamiento, la explotación e intercambio de recursos, el registro material, las prácticas funerarias, el control del agua, los análisis de isótopos estables, los eventos climáticos o las distintas series de C14, entre otros. En cambio, para la periferia, donde apenas existen yacimientos excavados, estos indicadores arqueológicos se han ceñido exclusivamente al modelo de asentamiento, la explotación de recursos y el escaso registro material asociado.

El análisis comparado de estos indicadores permite reconocer diferencias a nivel general sino entre las distintas comarcas limítrofes de La Mancha. La clave sigue siendo encontrar una explicación al porqué de estas diferencias, más allá de los planteamientos teóricos clásicos fundamentados en evidencias materiales, la mayoría de las veces poco concluyentes. El asentamiento a fecha de hoy sigue siendo el único indicador capaz de relacionar unos territorios con otros. En la periferia, la gran atomización de yacimientos y la más que probable interdependencia de unos poblados con otros, contrasta con la escasa potencia de su registro arqueológico. Ello puede indicar tanto el carácter estacional de muchos de ellos frente al carácter permanente de unos pocos. En el centro predomina la ocupación y abandono de yacimientos sin un patrón lógico de desarrollo.

La falta de uniformidad en los más de 700 años de ocupación del territorio impide establecer una definición real del Bronce de La Mancha. No sólo la investigación ha evidenciado la existencia de diferencias tipológicas y cronológicas entre asentamientos de la penillanura, sino en sus homólogos de la periferia. El solapamiento de fechas de $\mathrm{C} 14$ entre los diferentes yacimientos estudiados muestra una discontinuidad en el asentamiento, con alternancia de fases, no necesariamente sincrónicas, que hacen que cada yacimiento tenga un desarrollo cronológico independiente o solapado. La atomización de La Mancha puede responder a un modelo de poblamiento basado en el desplazamiento. Un desplazamiento coyuntural motivado 
por la explotación eficiente del entorno inmediato. Así, podemos encontrar tanto yacimientos que han estado más o menos habitados durante toda la Edad del Bronce, como es el caso del Azuer, o aquellos cuyas ocupaciones, aún siendo de largo recorrido, no se perpetúan en el tiempo. Llama la atención cómo poblados como el Acequión desaparecen (Balsera et al. 2016: 336) coincidiendo con la supuesta época de bonanza documentada en otros yacimientos de La Mancha, coincidiendo con un aumento de población de la fase III del Azuer (1800-1600 a.C.).

En esta dinámica de desplazamientos, la periferia debió ser destino frecuente, sobre todo en períodos de carestía. En este modelo de poblamiento itinerante encajaría perfectamente la diversidad tipológica del asentamiento manchego. Esta heterogeneidad en el asentamiento lo aleja de esa visión sólida que siempre ha caracterizado al Bronce de La Mancha. La discontinuidad puede ser debida a la existencia de una sociedad con base itinerante. Con este nuevo planteamiento, habría que volver a analizar la verdadera relación que existe entre poblados, sin importarnos el sector de La Mancha en el que se encuentran. Y lo que es más importante, tratar de establecer si existe una relación directa con los condicionantes climáticos y de otro tipo, con las dinámicas de ocupación del territorio. Para ello, resulta fundamental plantear una revisión de la ocupación de las comarcas periféricas y su verdadero papel en el desarrollo del Bronce de La Mancha.

En este proceso los poblados debieron disfrutar de una cierta autonomía derivada de su propia dinámica interna, aunque beneficiándose de un mismo sistema común para toda La Mancha. Esta supuesta autonomía ha sido identificada en zonas como el corredor de Almansa, en donde el equipo de la Universidad de Alicante ha creído reconocer una "unidad cultural" independiente del propio Bronce de La Mancha (Hernández Pérez et al. 1994; García Atiénzar 2011; Jover Maestre et al. 2014). Algo similar ocurre si hablamos de los Montes de Toledo o la serranía de Cuenca. En estos dos últimos, la orografía es el factor determinante en la formación de una identidad cultural propia. Mientras que el asentamiento en el sector oriental de los Montes de Toledo se encuentra condicionado por lo escarpado de sus cimas, lo que restringe el tamaño de los poblados, en las estribaciones de la serranía de Cuenca en contacto con La Mancha, más accesibles, los asentamientos son por regla general mayores y de más entidad (fig. 4). Con todo, este patrón de asentamiento tiende a homogeneizarse conforme nos acercamos a la penillanura y son las elevaciones contenidas en ellas las que soportan la totalidad de la ocupación en altura. Estos yacimientos son los que realmente caracterizan el Bronce de La Mancha, siendo las motillas las excepciones del mismo.

La cuestión, por tanto, sigue siendo determinar el momento en el que se produce la ocupación de la periferia y las causas que lo provocan y la relación entre los distintos territorios. Lo cierto es que su abandono debió ser parejo al despoblamiento del resto de la penillanura, desconociendo aún las causas que lo provocaron (Blasco Bosqued y Lucas Pellicer 2001).

\section{CONSIDERACIONES FINALES}

Gracias a estas décadas de incesante investigación en La Mancha, la Edad del Bronce aparece definida como una tupida red de asentamientos distribuida a lo largo de todo el territorio con unas características propias y cuyo fin último es la subsistencia en un medio cambiante. En la mayoría de los manuales, la Edad del Bronce de La Mancha se entiende como una arqueología de asentamientos caracterizada por morras, motillas y castillejos. El problema es que en los últimos años se ha desvelado una realidad mucho más compleja, con gran variedad de yacimientos que no necesariamente encajan en este modelo y con un condicionante climático que puede haber influido en su desarrollo.

En esta nueva revisión sigue sin quedar clara ni la conexión entre yacimientos ni el papel de las comarcas limítrofes. La división de poblados en altura y en llano, catalogados genéricamente como morras, castillejos y motillas no funciona para regiones limítrofes como los Montes de Toledo. No es lo mismo un poblado en altura localizado sobre una de las múltiples sierras que se distribuyen en La Mancha (morras y castillejos), que un poblado en altura de los Montes de Toledo, cuya accesibilidad lo hace casi impracticable. Tampoco esta generalización funciona en el caso de las motillas, que son verdaderas excepciones al poblamiento de la Edad del Bronce de La Mancha. En este sentido, al igual que debemos entender la periferia como un complemento del modelo válido para el conjunto de La Mancha, debemos hacer lo propio con las motillas. Su concentración mayoritaria en torno a la zona lagunar de la provincia de Ciudad Real, su largo desarrollo cronológico y su asociación con el agua las ha hecho merecedoras de una consideración diferente al resto de asentamientos. Determinar las causas de la sucesión 
de eventos documentados tanto en motillas como en el resto de asentamientos en altura excavados, más allá de definir series de radiocarbono, puede ser un buen punto de partida.

Los más de setecientos años de Edad del Bronce dejan entrever un largo crecimiento que, lejos de ser homogéneo, aparece condicionado tanto por factores climáticos cambiantes que resultan en posibles movimientos de población (Lillios et al. 2016), como por desarrollos internos y cambios sociales (Gilman 1999). Con este panorama, convertir el asentamiento en principal paradigma para explicar el desarrollo del Bronce de La Mancha no parece que haya servido para mucho y, pese al punto muerto actual, sigue siendo la base de la investigación.

Las claves de este estancamiento son tanto la falta de datos a nivel regional como la enorme atomización de las investigaciones y la escasa atención prestada a las comarcas limítrofes. El resultado ha sido constatar el predominio de lo local en los proyectos. La consecuencia es la exclusión de zonas centrales de La Mancha como el S de las provincias de Cuenca y Toledo, al no estar asociadas a ningún proyecto de investigación específico (fig. 1, b, i). Circunstancia a tener en cuenta de cara a un análisis de la Edad del Bronce en su conjunto. Esto vuelve a poner en evidencia la fragilidad del método y demanda el desarrollo y consolidación de nuevos planteamientos (Lillios 2018).

En la definición clásica del Bronce de La Mancha se echa en falta el papel de la periferia. Las comarcas limítrofes debieron de retroalimentarse y contribuir al desarrollo de toda la región. Al principio de este artículo planteábamos la posibilidad de que dicha ocupación fuera consecuencia bien de un momento de crecimiento puntual, cuya presión demográfica provocara la ocupación de la periferia o su contrario, como resultado de una crisis. A lo largo de este trabajo hemos visto que el registro arqueológico conocido hasta ahora habilita ambas teorías, dependiendo el enfoque teórico del que se parta inicialmente (Brodsky y Gilman 2013). Sea como fuere, lo que parece claro es que una vez ocupada esta periferia su desarrollo fue parejo al del resto de La Mancha, compartiendo también su ocaso.

En este nuevo planteamiento se admite la posibilidad de la existencia de una sociedad itinerante como medio de gestionar un medio cambiante. Este modelo de poblamiento basado en el desplazamiento justificaría tanto la atomización de la zona como la falta de continuidad cronológica entre asentamientos. Como hemos visto, este modelo cuestionaría la funcionalidad estrictamente defensiva de muchos de estos yacimientos.
Pese a la disparidad de indicadores arqueológicos para explicar el Bronce de La Mancha, el patrón de asentamiento y el territorio siguen siendo la principal fuente de información. Existen elementos materiales y geográficos suficientes para establecer una clara diferencia entre el asentamiento localizado en la penillanura de La Mancha, incluidas las elevaciones montañosas que contiene, y su periferia. Entre esta periferia, los Montes de Toledo funcionan como una entidad geográfica y cultural independiente del resto de La Mancha, aunque formando parte de un mismo proceso. Algo similar ocurre con las zonas montañosas limítrofes de las actuales provincias Albacete, Ciudad Real y Cuenca. Un vasto territorio equiparable en extensión al propio centro manchego.

De esta forma el Bronce de La Mancha se entiende como un territorio compuesto de diferentes identidades que se complementan entre sí. La formación y consolidación de la periferia está relacionada con una adaptación en altura al modelo de asentamiento característico de la penillanura. Si asumimos la existencia de una homogeneidad de yacimientos para el conjunto de La Mancha, incluidas sus comarcas periféricas, nos falta por conocer el cuándo y el porqué de la ocupación de estas últimas. En este proceso desconocemos tanto el papel de la población autóctona como si estos desplazamientos responden a la necesidad de asegurar la subsistencia en condiciones desfavorables o a un aumento de población producto de un desarrollo económico puntual.

En este artículo se ha evidenciado el fuerte contraste entre la falta de datos y la multitud de hipótesis y teorías generados en las últimas décadas. Quizá las únicas novedades recientes hayan sido tanto recuperar el factor climático como posible motor de cambio como rescatar la vieja idea de un registro funerario complejo. Ambos indicadores no dejan de ser una nueva vuelta de tuerca al clasicismo imperante, en su intento de explicar este fenómeno cultural desde diferentes postulados teóricos y sus derivados. El futuro pasa por un cambio de método y asumir la existencia de diferentes identidades en un territorio que no es tan homogéneo como se había dado a entender.

\section{AGRADECIMIENTOS}

Una de las dificultades de este artículo ha sido formalizar el relato de las múltiples intervenciones y proyectos que desde la década de los ochenta del pasado siglo se vienen desarrollando en La Mancha. En la argumentación se ha recurrido tanto a trabajos antiguos, 
alguno de ellos ya superado, como recientes. Siendo único responsable de los errores que haya podido cometer, agradezco a Agustín Diez Castillo la ayuda y comentarios hechos al borrador y a los evaluadores anónimos sus acertadas sugerencias.

\section{BIBLIOGRAFÍA}

ABARQUERO MORAS, F. J.; DELIBES DE CASTRO, G. (1997): La presencia de Cogotas I en el País Valenciano: acotaciones al tema desde una perspectiva meseteña, SagvntvmPLAV 30, 115-134.

ALMAGRO GORBEA, M. (1988): Las culturas de la Edad del Bronce y de la Edad del Hierro en Castilla-La Mancha, I Congreso de Historia de Castilla-La Mancha, Junta de Comunidades de Castilla-La Mancha, 163-180.

ALMAGRO GORBEA, M. (1997): La Edad del Bronce en la Península Ibérica: periodización y cronología, Sagvntvm-PLAV 30 (Homenaje a Milagros Gil-Mascarell, vol. II), 217-229.

ÁlVARO, E.; PEREIRA SIESO, J. (1990): El cerro del Bu (Toledo), Actas del I Congreso de Arqueología de la Provincia de Toledo, Toledo, 201-213.

BALSERA NIETO, V. (2017): Demografía y poblamiento en la meseta sur entre el 5500 y el 1200 CAL BC una perspectiva desde el radiocarbono, Tesis doctoral, Universidad Autónoma de Madrid.

BALSERA, V.; DÍAZ DEL RÍO, P.; DÍAZ ZORITA, M.; BOCHERENS, H.; WATERMAN, A.; THOMAS, J.; PEATE, D.; MARTÍNEZ NAVARRETE, M. I. (2016): El Acequión: paleodieta y movilidad humana durante la Edad del Bronce de La Mancha, Actas de la I Reunión Científica de Albacete, Albacete, 331-343.

BARCIELA GONZÁLEZ, V. (2012): Tecnología del marfil en la Edad del Bronce de la Meseta Sur (España), Actas del Coloquio Internacional Marfil y Elefantes en la Península Ibérica y el Mediterráneo (A. Banerjee, J. A. López Padilla, T. X. Schumacher, eds.), Alicante, 199-214.

BENÍTEZ DE LUGO ENRICH, L. (2010): Las motillas del Bronce de La Mancha. Treinta años de investigación arqueológica, Arqueología, sociedad, territorio y paisaje. Homenaje a Maria Dolores Fernández Posse (P. Bueno, A. Gilman, C. Martín, J. Sánchez Palencia, eds.), Madrid, 141-162.

BENÍTEZ DE LUGO ENRICH, L. (2011): Orígenes, desarrollo y ocaso de la cultura del Bronce de La Mancha. Nuevas aportaciones a la interpretación de los procesos de transformación y cambio en el Alto Guadiana durante la prehistoria reciente, QPAC 29, 47-75.

BENÍTEZ DE LUGO ENRICH, L. (2018): Rituales funerarios neolíticos, calcolíticos y de la Edad del Bronce en la provincia de Ciudad Real: Cerro Ortega (Villanueva de la Fuente) y Castillejo del Bonete (Terrinches), Anejos a CUPAUAM 3, 153-168. DOI: https://doi.org/10.15366/ane3.rubio2018.011
BENÍTEZ DE LUGO ENRICH, L.; MEJÍAS MORENO, M. (2016): Hidrogeología y captación de aguas subterráneas en La Mancha durante la prehistoria reciente: la gestión de los recursos hídricos en la cultura de las Motillas, APL XXXI, 137-168.

BENÍTEZ DE LUGO ENRICH, L.; MEJÍAS MORENO, M.; LÓPEZ GUTIÉRREZ, J.; ÁLVAREZ GARCÍA, H.J.; PALOMARES ZUMAJO, N.; MATA TRUJILLO, E.; MORALEDA SIERRA, J.; MENCHÉN HERREROS, G.; FERNÁNDEZ MARTÍN, S.; SALAZAR-GARCÍA, D. C.; ODRIOZOLA LLORET, C.; BENITO SÁNCHEZ, M.; LÓPEZ SÁEZ, J. A. (2014): Aportaciones hidrogeológicas al estudio arqueológico de los orígenes del Bronce de La Mancha: la cueva monumentalizada de Castillejo del Bonete (Terrinches, Ciudad Real-España), TP 71 (1), 76-94.

DOI: https://doi.org/10.3989/tp.2014.12125

BENÍTEZ DE LUGO ENRICH, L.; MORALEDA, J.; SÁNCHEZ, J. L.; ÁLVAREZ , H. J.; MOLINA, M.; GARRIDO, M. A.; HERMANA, F.; RODRÍGUEZ, D. (2007): Problemática en la gestión de vigilancias ambientales para grandes obras y la corrección del impacto en el patrimonio arqueológico: el caso de La Villeta (Ciudad Real) en el Aeropuerto de Ciudad Real, Actas del I Congreso de Patrimonio Histórico de Castilla-La Mancha. La gestión del Patrimonio Histórico regional, Valdepeñas, 203-217.

BERNABEU, J.; JIMÉNEZ-PUERTO, J.; ESCRIBÁ, P.; PARDOGORDÓ, S. (2018): C14 y poblamiento en las comarcas centro-meridionales del País Valenciano (c. 7000-1500 cal BC), Recerques del Museu d'Alcoi 27, 35-48.

BLANCO GONZÁLEZ, A.; LILLIOS, K.; LÓPEZ SÁEZ, J.; DRAKE, B. (2018): Cultural, Demographic and Environmental Dynamics of the Copper and Early Bronze Age in Iberia (3300-1500 BC): Towards an Interregional Multiproxy Comparison at the Time of the $4.2 \mathrm{ky}$ BP Event, World Prehistory 31, 1-79.

DOI: https://doi.org/10.1007/s10963-018-9113-3

BLASCO BOSQUED, C. (1995): Aproximación a las relaciones entre la Meseta y el sureste durante la Edad del Bronce, Verdolay 7, 111-115.

BLASCO BOSQUED, C.; LUCAS PELLICER, M. R. (2001): Problemática del Bronce Final en la Meseta, SPAL 10, 221-233.

DOI: https://doi.org/10.12795/spal.2001.i10.15

BRODSKY, M.; GILMAN, A. (2013): Bronze Age political landscapes in La Mancha, The Prehistory of Iberia (M. Cruz Berrocal, L. García Sanjuán, A. Gilman, coords.), Nueva York, 157-185.

BUENO RAMÍREZ, P.; BARROSO BERMEJO, R.; BALBÍN BERHMANN, R. (2007): Agricultores y metalúrgicos en la Meseta Sur, Prehistoria y Protohistoria de la Meseta Sur (J. Pereira Sieso, coord.), Toledo, 57-94. 
BUENO RAMÍREZ, P.; BARROSO BERMEJO, R.; BALBÍN BEHRMANN. R. (2010): Entre lo visible y lo invisible: registros funerarios de la prehistoria reciente de la meseta sur, Arqueología, sociedad, territorio y paisaje. Homenaje a Maria Dolores Fernández Posse (P. Bueno, A. Gilman, C. Martín, J. Sánchez Palencia, eds.), Madrid, 53-74.

CARROBLES SANTOS, J.; MÉNDEZ CABEZA, M. (1991): Introducción al estudio del Calcolítico en La Jara toledana, Anales Toledanos XXVIII, 7-23.

CARROBLES SANTOS, J.; RUIZ TABOADA, A. (eds.) (2002): Actas del II Congreso de Arqueología de la Provincia de Toledo. La Mancha Occidental y la Mesa de Ocaña, Toledo.

CHAPMAN, R. (1990): Emerging complexity: The later prehistory of south-east Spain, Iberia and the west Mediterranean, Cambridge University Press.

DOI: https://doi.org/10.1017/CBO9780511735486

CHAPMAN, R. (2008): Producing Inequalities: Regional Sequences in Later Prehistoric Southern Spain, Journal of World Prehistory 21 (3), 195-260.

DOI: https://doi.org/10.1017/s10963-008-9014-y

DAVIDSON, I. (1980): Transhumance, Spain and ethnoarchaeology, Antiquity 54 (211), 144-147.

DOI: https://doi.org/10.1017/S0003598X00103035

DÍAZ ANDREU, M. (1994): La Edad del Bronce en la provincia de Cuenca, Serie Arqueología conquense 13, Cuenca.

ESTAVILLO VILLAUMBROSA, E. (1950): Yacimientos arqueológicos de Campo de Criptana (La Mancha), Actas y Memorias de la Sociedad Española de Antropología 25, 37-71.

FERNÁNDEZ MARTÍN, S. (2005): Estudio morfométrico de la producción cerámica del yacimiento arqueológico de la edad del bronce de la motilla del Azuer (Daimiel, Ciudad Real), Espacio y Territorio 2, 18-30.

FERNÁNDEZ MIRANDA, M.; CARROBLES SANTOS, J. (eds.) (1994): La Edad del Bronce en Castilla La Mancha: actas del Simposio, 1990, Toledo.

FERNÁNDEZ MIRANDA, M.; FERNÁNDEZ POSSE, M. D.; MARTÍN, C.; MONTERO RUIZ, I.; ROVIRA LLORENS, S. (1996): Changes in Bronze Age metallurgy as depicted by laboratory analysis: The" La Mancha"(Spain) model, Archaeometry 94, 25-34.

FERNÁNDEZ POSSE, M. D.; GILMAN, A.; MARTÍN, C. (1996): Consideraciones cronológicas sobre la Edad del Bronce de La Mancha, Complutum, 6 (Extra II), 111-137.

FERNÁNDEZ POSSE, M. D.; GILMAN, A.; MARTIN, C. (2001): Arqueología territorial. El ejemplo del poblamiento de la Mancha Oriental, La Edad del Bronce ¿Primera Edad de Oro de España (M. Ruiz-Gálvez, coord.), Barcelona, 121-137.

FERNÁNDEZ POSSE, M. D.; GILMAN, A.; MARTÍN, C.; BRODSKY, M. (2008): Las comunidades agrarias de la Edad del Bronce en La Mancha Oriental (Albacete), Madrid.

FERNÁNDEZ POSSE, M. D.; MARTíN, C. (1991): El Calcolítico y la Edad del Bronce en la Meseta, Boletín de la Asociación de Amigos de la Arqueología 30-31, 75-86.
FERNÁNDEZ POSSE, M. D.; MARTÍN, C. (2007): La Edad del Bronce, Prehistoria y Protohistoria de la Meseta Sur (J. Pereira Sieso, coorc.), Toledo, 105-124.

FRANK, A. (1993): Bronze Age World System Cycles. Current Anthropology 34, 383-429. DOI: https://doi.org/10.1086/204184

GALÁN SAULNIER, C. (1994): La cerámica del Bronce de La Mancha, Actas del Simposio 1990, La Edad del Bronce en Castilla La Mancha, Toledo, 5-36.

GALÁN SAULNIER, C. (2016): El yacimiento arqueológico de Los Dornajos (La Hinojosa, Cuenca), Akatros SL.

GALÁN SAULNIER, C. (2018): A propósito de las cerámicas Dornajos de Castillejo del Bonete, Anejos a Cuadernos de Prehistoria y Arqueología 3, 169-184. DOI: https://doi.org/10.15366/ane3.rubio2018.012

GARCÍA ATIÉNZAR, G. (2011): VII-IV milenio cal BC. El asentamiento prehistórico de Benàmer: consideraciones sobre la ocupación y explotación del territorio en el valle medio del Serpis, Benámer (Muro de Alcoi, Alicante) Mesolíticos y Neolíticos en las tierras meridionales valencianas (F. J. Jover, P. Torregrosa, E. López, eds.), València, 301-316.

GARCÍA GÓMEZ, E.; RUIZ TABOADA, A.; PEREIRA SIESO, J. (2020): El vareo de bellotas: pervivencia de una técnica de recolección prehistórica en el bosque mediterráneo, Complutum 31, 159-176.

GARCÍA HUERTA, R.; MORALES , J. (2004): Un yacimiento de fondos de cabaña: Las Saladillas (Alcázar de San Juan, Ciudad Real), La Península Ibérica en el II milenio a. C.: Poblados y fortificaciones (R. García Huerta, F. J. Morales, coord.), Cuenca, 233-274.

GARCÍA MARTÍN, M. (1991): Cañadas, cordeles y veredas, Junta de Castilla y León.

GIL-MASCARELL BOSCÀ, M. (1985): El final de la Edad del Bronce: estado actual de la investigación, Arqueología del País Valenciano. Panorama y perspectivas, Anejo de la Revista Lucentum, Alicante, 141-152. DOI: https://doi.org/10.14198/LVCENTVM1985.Anejo.08

GIL-MASCARELL BOSCÀ, M. (1995): Algunas reflexiones sobre el Bronce Valenciano, Sagvntvm-PLAV 28, 63-73.

GILMAN, A. (1995): Prehistoric Europeans Chiefdoms. Rethinking "Germanic" Societies, Foundations of social inequality (T. D. Price, G. M. Feinman, eds.), Plenum Press, 235-251.

DOI: https://doi.org/10.1007/978-1-4899-1289-3_9

GILMAN, A. (1999): Veinte años de Prehistoria funcionalista en el sureste de España, Boletín del Seminario de Estudios de Arte y Arqueología, 65, 73-98.

GILMAN, A.; FERNÁNDEZ POSSE, M. D.; MARTÍN, C. (2000): Avance de un estudio del territorio del Bronce manchego, Zephyrus, 53-54, 311-322.

HERNÁNDEZ PÉREZ, M. (2016): Arqueología en Albacete (20002015). De nuevo entre la decepción y la esperanza, Actas de la I Reunión Científica de Albacete, Albacete, 19-51. 
HERNÁNDEZ PÉREZ, M.; SIMÓN GARCÍA, J. L. (1994): La Edad del Bronce en el corredor de Almansa (Albacete). Bases para su estudio, Actas del Simposio 1990, La Edad del Bronce en Castilla La Mancha, Toledo, 201-242.

HERNÁNDEZ PÉREZ, M.; SIMÓN GARCÍA, J. L.; LÓPEZ MIRA, J. A. (1994): Agua y poder. El cerro de El Cuchillo (Almansa, Albacete), Serie Patrimonio Histórico Arqueología, Castilla La Mancha.

HERVÁS Y BUENDÍA, I. (1899): La Motilla de Torralba, Mondoñedo.

HINZ, M.; SCHIRRMACHER, J.; KNEISEL, J.; RINNE, C.; WEINELT, M. (2019): The Chalcolithic-Bronze Age transition in southern Iberia under the influence of the $4.2 \mathrm{ka}$ BP event? A correlation of climatological and demographic proxies, Journal of Neolithic Archaeology, 6 december, DOI: https://doi.org/10.12766/jna.2019.1

HODDER, I.; HUTSON, S. (2003): Reading the past: current approaches to interpretation in archaeology, Cambridge University Press.

DOI: https://doi.org/10.1017/CBO9780511814211

JIMÉNEZ DE GREGORIO, F. (1970): Diccionario de los pueblos de la provincia de Toledo hasta finalizar el siglo XVIII, Población, sociedad, economía e historia, Toledo.

JIMÉNEZ DE GREGORIO, F. (2001): Aproximación al mapa arqueológico del occidente provincial toledano, Actas de las primeras jornadas de arqueología de Talavera de la Reina $y$ sus tierras, Toledo, 5-38.

JORDÁ PARDO, F.; PASTOR MUÑOZ, F. J.; RIPOLL LÓPEZ, S. (1999): Arte rupestre paleolítico y postpaleolítico al aire libre en los Montes de Toledo occidentales (Toledo-Casti1la La Mancha, España): noticia preliminar, Zephyrus LII, 281-296.

JOVER MAESTRE, F. J.; GARCÍA ATIÉNZAR, G.; LÓPEZ PADILLA, J. A. (2019): Del fondo del valle a lo alto de la montaña: cambios en la organización del hábitat y del territorio en el Este de la península Ibérica entre el Calcolítico y la Edad del Bronce, Recerques del Museu d'Alcoi 28, 79-100.

JOVER MAESTRE, F. J.; LÓPEZ PADILLA, J.A. (2013): La producción textil durante la Edad del Bronce en el cuadrante suroriental de la Península Ibérica: materias primas, productos, instrumentos y procesos de trabajo, Zephyrus LXXI, 149-171.

JOVER MAESTRE, F. J.; LÓPEZ PADILLA, J. A.; GARCÍADONATO LAYRÓN, G. (2014): Radiocarbono y estadística Bayesiana: aportaciones a la cronología de la Edad del Bronce en el extremo oriental del sudeste de la península Ibérica, Sagvntvm-PLAV 46, 41-69.

DOI: https://doi.org/10.7203/SAGVNTVM.46.3479

JOVER MAESTRE, F. J.; MARTÍNEZ MONLEÓN, S.; LÓPEZ PADILLA, J. A. (2018): Sobre la estructura poblacional de las sociedades del sur del bronce valenciano, Zephyrus LXXXII, 93-117.

DOI: https://doi.org/10.14201/zephyrus20188293117
LENGUAZCO GONZÁLEZ, R. (2016): Ocupación del territorio y aprovechamiento de recursos en el bronce de La Mancha: las motillas y su territorio de explotación directa, Tesis Doctoral, Universidad Autónoma de Madrid.

LENGUAZCO GONZÁLEZ, R. (2018): Poblamiento durante la Edad del Bronce en los Ojos del Guadiana: el yacimiento arqueológico de la Motilla de Mari López y su entorno, Anejos a CuPAUAM 3, 185-192

DOI: https://doi.org/10.15366/ane3.rubio2018.013

LILLIOS, K. T. (2018): Veinte años de arqueología de la Prehistoria tardía en la Península Ibérica. Mirando hacia atrás y hacia delante, TP 75 (2), 203-222.

DOI: https://doi.org/10.3989/tp.2018.12212

LILLIOS, K. T.; BLANCO GONZÁLEZ, A.; DRAKE, B. L.; LÓPEZ SÁEZ, J. A. (2016): Mid-late Holocene climate, demography, and cultural dynamics in Iberia: A multi-proxy approach, Quaternary Science Reviews 135, 138-153. DOI: https://doi.org/10.1016/j.quascirev.2016.01.011

LÓPEZ FERNÁNDEZ, F. J. (1990): Poblados de altura de la Edad del Bronce en las sierras del Picón y Piedrabuena (Ciudad Real). Contribución al análisis espacial del territorio, TP 47, 339-350. DOI: https://doi.org/10.3989/tp.1990.v47.i0.579

LÓPEZ PADILLA, J. A. (2006): Distribución territorial y consumo de botones de perforación en "V" en el ámbito argárico, $T P$ 63 (2), 93-116.

DOI: https://doi.org/10.3989/tp.2006.v63.i2.19

LÓPEZ SÁEZ, J. A.; PÉREZ DÍAZ, S.; GARCÍA GÓMEZ, E.; ALBA SÁNCHEZ, F. (2019): Historia de la vegetación y los paisajes de Toledo, Toledo.

LÓPEZ SÁEZ, J. A.; SÁNCHEZ, F.; NÁJERA COLINO, T.; MOLINA GONZÁlEZ, F.; PÉREZ DÍAZ, S.; RUIZ, S. (2014): Paleoambiente y sociedad en la Edad del Bronce de La Mancha: la Motilla del Azuer, CPUG 24, 391-422.

MARTÍN MORALES, C. (1973): La morra de Quintanar, I Jornadas de Arqueología de Albacete, 57-73.

MARTÍN MORALES, C.; FERNÁNDEZ-MIRANDA, M.; FERNÁNDEZ POSSE, M.; GILMAN, A. (1993): The Bronce Age of La Mancha, Antiquity 67, 23-45. DOI: https://doi.org/10.1017/S0003598X00045038

MARTÍNEZ MORATALLA, J.; PIQUERAS, I.; SERRANO, P. A. (2002): Patrimonio arqueológico y espacios naturales en peligro ante las centrales eólicas, Instituto de Estudios Albacetenses 4, 485-497.

MARTÍNEZ NAVARRETE, M. I. (1988): Morras, motillas y castillejos: ¿Unidad o pluralidad cultural durante la Edad del Bronce en La Mancha?, Homenaje a Samuel de los Santos, Albacete, 81-92.

MARTÍNEZ PEÑARROYA, J. (2012): Prehistoria de los recintos fortificados en la Meseta Sur peninsular, Cuadernos de Arquitectura y Fortificación 0, 09-54.

MARTÍNEZ SANTA-OLALLA, J. (1951): El “crannog” de la laguna de Acequión en la provincia de Albacete, Anales del Seminario de Historia y Arqueología de Albacete, 1, 5-12. 
MEJÍAS MORENO, M.; BENÍTEZ DE LUGO, L.; LÓPEZ-SÁEZ, J. A.; ESTEBAN, C. (2015): Arqueología, hidrogeología y medio ambiente en la Edad del Bronce de la Mancha: la Cultura de las Motillas, Madrid.

MOLINA, F.; NÁJERA, T.; ARANDA, G.; SÁNCHEZ, M.; HARO, M. (2005): Recent fieldwork at the Bronze Age fortified site of Motilla del Azuer (Daimiel, Spain), Antiquity 79 (306), 223-235.

MORÍN DE PABLOS, J.; LÓPEZ RECIO, M.; SÁNCHEZ HIDALGO, F.; LÓPEZ LÓPEZ, G.; PÉREZ-JUEZ GIL, A.; REGIDOR IPIÑA, D. (2007): El Reino de Don Quijote de La Mancha. Nuevos datos sobre la ocupación prehistórica de la Cuenca Media del Guadiana, Actas de las I Jornadas de Arqueología en Castilla-La Mancha (Cuenca, 2005), Cuenca, 279-302.

NÁJERA, T. (1982): La Edad del Bronce en La Mancha Occidental, Tesis Doctoral inédita, Universidad de Granada.

NÁJERA, T.; JIMÉNEZ BROBEIL, S.; MOLINA, F.; DELGADO, A.; LAFFRANCHI, Z. (2012): La aplicación de los métodos de la antropología física a un yacimiento arqueológico: la Motilla del Azuer, $C P U G$ 22, 149-183.

NÁJERA, T.; MOLINA, F. (1977): La Edad del Bronce en La Mancha, excavaciones en las motillas del Azuer y Los Palacios, CPUG 2, 251-300.

NÁJERA, T.; MOLINA, F. (2004): Las motillas: un modelo de asentamiento con fortificación central en la Llanura de La Mancha, La Península Ibérica en el II milenio antes de Cristo, poblados y fortificaciones (R. García Huerta, F. J. Morales, coords.), Cuenca, 173-214.

NÁJERA, T.; MOLINA, F.; JIMÉNEZ BROBEIL, S.; SÁNCHEZ ROMERO, M.; AL OUMAOUI, I.; ARANDA, G.; DELGADO HUERTAS, A.; LAFFRANCHI, Z. (2010): La población infantil de la Motilla del Azuer: un estudio bioarqueológico, Complutum 21 (2), 69-102.

NIETO GALLO, G.; SÁNCHEZ MESEGUER, J. (1980): El Cerro de la Encantada. Granátula de Calatrava (Ciudad Real), Excavaciones Arqueológicas en España 113, Madrid.

OCAÑA CARRETÓN, A. (2002): Las Lagunas de Ruidera durante la Edad del Bronce: un territorio jerarquizado, TP 59 (1), 167-177.

DOI: https://doi.org/10.3989/tp.2002.v59.i1.217

PANADERO MOYA, M.; PILLET CAPDEPÓN, F. (1999): Las comarcas de la región, La España de las Autonomías (J. García Alvarado, J. A. Sotelo, eds.), Madrid, 291-330.

PEREIRA SIESO, J. (2007): Prehistoria y Protohistoria de la Meseta Sur (Castilla-La Mancha), Añil.

PEREIRA SIESO, J. (2012): La tumba de la casa del Carpio (Belvis de la Jara, Toledo). Un enterramiento femenino de época orientalizante, La arqueología funeraria desde una perspectiva de género (L. Prados, C. López, J. Parra, coords.), Madrid, 201-214.

DOI: https://doi.org/10.15366/ar.funeraria2012.009
PEREIRA SIESO, J.; RUIZ TABOADA, A.; RODRÍGUEZ MONTERO, S. (2003): Proyecto Quercus: algunas consideraciones sobre la recolección y consumo de bellotas en la Provincia de Toledo, Actas del Congreso de la Naturaleza en la Provincia de Toledo, Toledo, 415-424.

RIVERA, D.; OBÓN, C.; DÍAZ-ANDREU, M. (1994): Estudio del aprovechamiento del medio natural en el yacimiento de la Edad del Bronce de El Recuenco (Cervera del Llano, Cuenca). Análisis paleobotánicos, TP 51 (2), 169-178.

DOI: https://doi.org/10.3989/tp.1994.v51.i2.456

ROMERA, A.; MORENO, J. (2015): La Edad del Bronce en el norte del Campo de Montiel (Alhambra, Ciudad Real): el caso del Cerro Bilanero. Primera valoración a partir de los sistemas de información geográfica, Revista de Estudios del Campo de Montiel 4, 109-140.

ROJAS RODRÍGUEZ MALO, J. M.; GÓMEZ LAGUNA, A.; CÁCERES GUTIÉRREZ, Y.; DE JUAN ARES, J. (2010): Los asentamientos del III y II milenio de Adc. En autovía de los viñedos. Tramo: Consuegra Tomelloso (P. K. 0+000A 74+600). La Serna, Casa de Antoñón I, Casa de los Castos, Santa Lucía, Varas del Palio, Casa de Antoñón II y Casa del Montón, Actas digitales de las II Jornadas de Arqueología de Castilla La Mancha (A. Madrigal Belinchón, M. Perlines Benito, eds.),Toledo.

ROWLANDS, M.; LARSEN, M.; KRISTIANSEN, K. (1987): Centre and Periphery in the Ancient World. Cambridge University Press.

RUIZ TABOADA, A. (1993): Producción y explotación económica en las estribaciones nororientales de los Montes de Toledo durante la Edad del Bronce, Complutum 4, 311-320.

RUIZ TABOADA, A. (1994): La motilla del Morrión y su entorno: un ejemplo de poblamiento en La Mancha noroccidental, La Edad del Bronce en Castilla- La Mancha: actas del Simposio (M. Fernández Miranda, J. Carrobles Santos, eds.), Toledo, 419-430.

RUIZ TABOADA, A. (1997): Asentamiento y subsistencia en La Mancha durante la Edad del Bronce: El sector noroccidental como modelo, Complutum 8, 57-72.

RUIZ TABOADA, A. (1998): La Edad del Bronce en la provincia de Toledo: La Mancha y su entorno, Toledo.

RUIZ TABOADA, A.; MONTERO, I. (2000): The pattern of use of stone and copper in central Spain during the Bronze Age, European Journal of Archaeology 3 (3), 350-369. DOI: https://doi.org/10.1179/146195700807860882

SÁNCHEZ HIDALGO, F.; LÓPEZ LÓPEZ, G.; ESCOLÁ MARTÍNEZ, M.; LÓPEZ RECIO, M.; MORIN DE PABLOS, J. (2010): Un yacimiento de la Edad del Bronce en altura en las estribaciones de los Montes de Toledo. Sierra de Altamira, Mohedas de la Jara (Toledo), Actas digitales de las II Jornadas de Arqueología de Castilla La Mancha (A. Madrigal Belinchón, M. Perlines Benito, eds.),Toledo. 
El factor límite en la formulación del discurso del Bronce de La Mancha: los Montes de Toledo como modelo

SÁNCHEZ JIMÉNEZ, J. (1948): La cultura algárica en la provincia de Albacete: notas para su estudio, Actas y Memorias de la Sociedad Española de Antropología, Etnografía y Prehistoria 23, 96-110.

SÁNCHEZ MESEGUER, J. L.; GALÁN, C. (2004): El Cerro de la Encantada, La Península Ibérica en el II Milenio a. C., Poblados y Fortificaciones (R. García Huerta, F. J. Morales, coords.), Cuenca, 115-172.

SANTISTEBAN, J. I.; MEDIAVILLA, R.; CELIS,A.; CASTAÑO, S.; LOSA, A. (2016): Millennial-scale cycles of aridity as a driver of human occupancy in central Spain?, Quaternary International 407, 96-109.

DOI: https://doi.org/10.1016/j.quaint.2016.02.021
SIMÓN GARCÍA, J. L. (1987): La Edad del bronce en Bonete y Fuente Álamo, Albacete.

TARRADELL, M. (1965): El problema de las diversas áreas culturales en la Península Ibérica en la Edad del Bronce, Miscelánea en Homenaje al Abate Breuil II, 423-430.

TARRADELL, M. (1969): La cultura del Bronce Valenciano. Nuevo ensayo de aproximación, Sagvntvm-PLAV 6, 7-30.

TORRES MAS, M. (2015): La Motilla del Azuer: un yacimiento arqueológico de interés cultural en Daimiel (Ciudad Real), III Jornadas de Historia de Daimiel, Daimiel, 15-30.

URBINA, D.; URQUIJO, C.; SÁNCHEZ, A.; ORTIZ, G. (1994): Arqueología y yacimientos minerales en el occidente de los Montes de Toledo, Zephyrus XLVII, 257-272. 